\title{
Effects of starvation, ammonium concentration, and photosynthesis on the UV-dependent accumulation of mycosporine-like amino acids (MAAs) in the coral Stylophora pistillata
}

\author{
J. Malcolm Shick ${ }^{1, *}$, Christine Ferrier-Pagès ${ }^{2}$, Renaud Grover ${ }^{2}$, Denis Allemand ${ }^{2,3}$ \\ ${ }^{1}$ School of Marine Sciences, University of Maine, 5751 Murray Hall, Orono, Maine 04469-5751, USA \\ ${ }^{2}$ Centre Scientifique de Monaco, Avenue Saint-Martin, 98000 Monaco, Principality of Monaco \\ ${ }^{3}$ UMR 1112 INRA-UNSA, University of Nice-Sophia Antipolis, Parc Valrose, BP 71, 06108 Nice Cedex 2, France
}

\begin{abstract}
This study addresses several unresolved questions regarding the biosynthesis, metabolism, regulation, and diversity of MAAs in zooxanthellate scleractinian corals. Starved colonies of Stylophora pistillata accumulated the same concentrations of mycosporine-like amino acids (MAAs) as fed corals after $28 \mathrm{~d}$ of exposure to photosynthetically available radiation (PAR) and ultraviolet radiation (UVR), suggesting that dietary MAAs are of little quantitative importance in this phototrophic symbiosis. Starved corals continued to accumulate MAAs and conserved them disproportionally compared with declining protein and chlorophyll $a$, indicating the priority placed on maintaining this UV-sunscreen defense. In 2 different colonies (SP1 and SP2) exposed to enriched (10 $\mu \mathrm{M})$ ammonium and PAR + UVR during starvation, the final concentrations of MAAs and chlorophyll a were identical. However, under ambient ammonium $(<0.4 \mu \mathrm{M})$, SP2 produced MAAs at the expense of chlorophyll $a$, whereas SP1 maintained chlorophyll a levels but synthesized less MAA. Ammonium consistently affected only the accumulation of primary, Symbiodinium-MAAs (mycosporine glycine, shinorine, porphyra-334, and mycosporine-2 glycine) and not secondary MAAs derived from the former, probably in the host's tissues. Mycosporine-2 glycine and palythine (a secondary MAA) were synthesized by SP1 but not SP2, suggesting (1) genotypic differences between the zooxanthellae in SP1 and SP2, and (2) a biosynthetic relationship between these 2 MAAs that we proposed previously. Exposure to UVR alone did not support large-scale biosynthesis of MAAs in S. pistillata, and accumulation of the full suite of MAAs required PAR + UVR; together with an inhibitory effect of DCMU, this indicates that photosynthesis is required for the UV-stimulated, de novo biosynthesis of MAAs. Cultures of zooxanthellae isolated from $S$. pistillata and exposed to PAR + UVR showed increased levels of shinorine, and some production of mycosporine-glycine. Host extract had no qualitative effect on the MAAs produced by these zooxanthellae.
\end{abstract}

KEY WORDS: Mycosporine-like amino acids (MAAs) $\cdot$ Coral $\cdot$ Zooxanthellae $\cdot$ Ultraviolet radiation $(\mathrm{UVR}) \cdot$ Dissolved ammonium $\cdot$ Photosynthesis

\section{INTRODUCTION}

Mycosporine-like amino acids (MAAs) efficiently absorb ultraviolet radiation (UVR) in the range 310 to $360 \mathrm{~nm}$ and harmlessly dissipate it as heat (Shick et al. 2000, Conde et al. 2004). They are widely distributed among marine organisms and have been much studied in zooxanthellate scleractinian and soft corals (reviewed by Shick et al. 1996, Dunlap \& Shick 1998, Gleason 2001, Karentz 2001, Shick \& Dunlap 2002, Banaszak 2003). Despite this extensive knowledge, fundamental questions remain concerning the biosyn- 
thesis, metabolism, regulation, and diversity of MAAs in corals.

Specifically, our present experiments address the following issues: (1) What proportion of the MAAs is produced by the zooxanthellae compared with that obtained by feeding? (2) Is the biosynthesis of MAAs in starved corals limited by nitrogen availability? (3) Does the de novo biosynthesis of MAAs require photosynthesis? (4) Does the coral affect the complement of MAAs that the zooxanthellae produce? (5) Are there intercolony (genotypic) differences in the biosynthesis and metabolism of MAAs?

Blockade of the early steps in the shikimic acid pathway using the herbicide glyphosate points to the pathway's involvement in the biosynthesis of MAAs in Stylophora pistillata, presumably by the zooxanthellae (Shick et al. 1999, Shick \& Dunlap 2002). Feedback inhibition by tyrosine also indicates that MAAs in cyanobacteria are produced via this route (Portwich \& Garcia-Pichel 2003).

The concentration of MAAs in zooxanthellate scleractinians decreases dramatically with increasing depth (e.g. Dunlap et al. 1986, Gleason \& Wellington 1995, Shick et al. 1995, Banaszak et al. 1998), largely owing to a bathymetric decline in the fluence of UVR (Gleason 2001). It is specifically UV-B (280 to $320 \mathrm{~nm}$ ) that stimulates the accumulation of MAAs in Stylophora pistillata (Shick et al. 1999).

Differences in water movement and photosynthetically available radiation (PAR, 400 to $700 \mathrm{~nm}$ ) across depths also affect the concentration of MAAs (Jokiel et al. 1997). In that study, however, concentrations of MAAs did not increase with irradiance in its lower range where there would have been a marked increase in photosynthesis, but increased only at higher levels of PAR where photosynthesis would already have been saturated. Conversely, Neale et al. (1998) reported a disproportional 21-fold increase in the MAA content of a dinoflagellate coincident with a 2.7-fold increase in photosynthesis when the PAR incident on the cultures was tripled. Thus, the biosynthesis of MAAs seems not simply to be a response to an increased, proportional flow of photosynthetically fixed carbon into the shikimic acid pathway, but part of a suite of responses to the stress of high irradiance (cf. Shick et al. 2000). This is particularly true because fluences of both PAR and UVR are highly correlated (Jokiel et al. 1997). As Lesser (2004) noted, there has been no definitive study on the effects of UVR or other environmental factors on the stoichiometry of photosynthetic carbon fixation, the flow of carbon into the shikimic acid pathway, and the accumulation of MAAs. Nevertheless, the inhibition of the accumulation of MAAs in cultured dinoflagellates by the herbicide DCMU (Carreto et al. 1990) confirms that photosynthesis is involved in their biosynthesis of MAAs.

Like other consumers, including sea anemones (Shick et al. 2002), corals may also obtain some MAAs from their prey. The relative contribution of such exogenous sources compared with endogenous (photosynthetic) production of MAAs has not heretofore been assessed experimentally (see Gleason 2001), which is a goal of our study. In the same context, we tested whether UVR alone in the absence of PAR would elicit the accumulation of MAAs in unfed corals, as it does in the red macrophyte Chondrus crispus (Karsten et al. 1998) and in the cyanobacterium Chlorogloeopsis sp. when grown heterotrophically (Portwich \& Garcia-Pichel 1999, 2000).

Gleason (2001) discerned an inverse relationship between MAA concentration and growth rate among different types of corals. He attributed this relationship to the high cost of synthesizing MAAs, a cost subtracted from resources allocated to growth under nutrient-limiting conditions. Because inorganic carbon is probably not limiting to photosynthesis in the zooxanthellae (Allemand et al. 1998), and corals receive all of the organic carbon needed for growth and respiration from their zooxanthellae, Gleason (2001) proposed that the low availability of nitrogen in oligotrophic reef waters might limit MAA production.

When starved, Stylophora pistillata increases its rate of uptake of ammonium from seawater, with the zooxanthellae becoming more enriched in nitrogen than the host (Grover et al. 2002). Because it is in the zooxanthellae where most of the ammonium is assimilated and where MAAs are produced de novo, we examined the effects of ambient and elevated ammonium concentrations on the accumulation of MAAs in starved specimens of $S$. pistillata. We also examined the effects of starvation and ammonium enrichment on the maintenance of the concentrations of zooxanthellae, chlorophyll $a$, and colony protein, to assess whether the UV-enhanced accumulation of MAAs may occur at the expense of other uses of nitrogen, and whether this is offset by the increased availability of inorganic nitrogen.

The complement of MAAs found in zooxanthellae freshly isolated from a symbiosis sometimes, but not always, matches that in the symbiosis; furthermore, cultured zooxanthellae (CZ) typically have a less diverse complement of MAAs than do the cnidarian hosts from which they were isolated (Banaszak \& Trench 1995, Shick et al. 1999, Banaszak et al. 2000, Shick \& Dunlap 2002). After the finding that heterotrophic consumers and their enteric bacteria can metabolically alter dietary MAAs (Dunlap \& Shick 1998), we suggested that the additional MAAs found in starved Stylophora pistillata colonies that were not present in a 
culture of zooxanthellae derived from this species of coral were produced in the host from a smaller suite of MAAs translocated from the zooxanthellae (Shick et al. 1999). This suggestion was based on the complementary kinetics of accumulation, first, of primary or 'Symbiodinium-MAAs' (collectively, all 4 of the MAAs produced by genotypically diverse cultures of Symbiodinium spp., i.e. mycosporine-glycine, shinorine, and porphyra-334 [Banaszak et al. 2000], plus mycosporine-2 glycine produced by cultured zooxanthellae originally from Galaxea fascicularis [J. M. Shick \& C. Ferrier-Pagès unpubl.]), and later, of 6 secondary MAAs. As the steady-state concentration of MAAs was approached, decreases in the primary MAAs were stoichiometrically balanced by increases in the secondary MAAs (Shick 2004). Here we test whether ammonium enrichment may be differentially manifested in primary and secondary MAAs in S. pistillata.

Qualitative differences between the MAA complements of the freshly isolated zooxanthellae (FIZ) and $\mathrm{CZ}$ might also occur if the zooxanthellae in hospite (within the host), receiving some precursor or signal from the host ('host factor': reviewed by Trench 1993), produce additional MAAs beyond those seen in culture (Banaszak \& Trench 1995). Accordingly, we analyzed the MAAs present in a culture of Symbiodinium sp. isolated from a colony of Stylophora pistillata originating in the Red Sea, grown with and without the addition of an extract of the host tissue from our experimental specimens of this coral.

Broadly, our experiments address the relative roles of biosynthesis by the zooxanthellae and feeding by the host as sources of MAAs in Stylophora pistillata, whether nitrogen limits MAA biosynthesis in this zooxanthellate coral, and the effects of UVR and PAR in the photosynthesis-dependent production of MAAs. Differences between experimental colonies in the complement of MAAs, the rate of accumulation of MAAs, and the ratio of primary to secondary MAAs are suggestive of genotypic differences in the metabolism of MAAs.

\section{MATERIALS AND METHODS}

Maintenance of corals. Prior to the experiments, asexually propagated colonies of Stylophora pistillata originating in the northern Red Sea (Gulf of Aqaba) were maintained in aquaria at the Centre Scientifique de Monaco as described in Shick (2004). Light sources, feeding regimen on Artemia sp. nauplii (batch Utah B2005), temperature, and salinity were as given in that paper.

Experimental aquarium. The experimental aquarium described in Shick et al. (1999) and Shick (2004) was used in all experiments, which were conducted at $27^{\circ} \mathrm{C}$ and $38 \mathrm{psu}$. Its design allowed the exposure of some corals to UVR in the same flowing seawater as unexposed controls, eliminating any statistical 'tank effect'. In those cases where corals were incubated in individual beakers, the aquarium was used as a water bath, and submersible magnetic stirrers operated continuously beneath the beakers, in which the pieces of coral were supported on nylon mesh above stirring bars. In all experiments done in beakers, the evaporation of seawater (which was changed daily) was prevented using UV-transparent film or spectral filters, as described below for individual experiments. Each day the beakers were washed in hot tapwater and rinsed in seawater, and the experimental nubbins were rotated among them. An International Light IL1400A radiometer, and SEL033 UV-A and SEL240B UV-B sensors, calibrated against a LiCor 1800UW scanning radiometer (Shick 2004), measured UVR in all experiments. PAR was measured by a LiCor LI-1000 DataLogger and 193SA $(4 \pi$, used in the maintenance and experimental aquaria) or 192SA ( $2 \pi$, used inside beakers) underwater quantum sensors. The irradiances incident on the experimental aquarium were $\mathrm{PAR}=60.1 \mathrm{~W} \mathrm{~m}^{-2}$, $\mathrm{UV}-\mathrm{A}=20.5 \mathrm{~W} \mathrm{~m}^{-2}$, and UV-B $=1.2 \mathrm{~W} \mathrm{~m}^{-2}$, measured with the LiCor scanning spectroradiometer (Shick 2004). Corals in all experiments were exposed to PAR for $12 \mathrm{~h} \mathrm{~d}^{-1}$, with UVR being present for the middle $8 \mathrm{~h}$ during this photoperiod.

Effect of feeding on accumulation of MAAs. Because zooxanthella populations and photosynthetic productivity are greater in Stylophora pistillata when the coral is fed (Titlyanov et al. 2001, Ferrier-Pagès et al. 2003, Houlbrèque et al. 2003), nubbins in our long-term experiments were fed Artemia sp. nauplii. However, Artemia sp. cysts and nauplii from diverse locations contain several MAAs and their presumed precursors — gadusols - in varying proportions (Grant et al. 1985). Therefore, we tested whether twice-weekly feeding of corals during 4 wk of exposure to PAR + UVR affected their accumulation of MAAs, compared with corals starved for the same period. At each feeding (which occurred after the UV lamps were turned off for the day), approximately $10 \mathrm{~g}$ (wet weight) of freshly hatched nauplii were placed in the experimental aquarium in which the seawater was continuously circulated by submersible pumps. Turnover of seawater in this flow-through aquarium was 3 to $4 \% \mathrm{~h}^{-1}$. Starved corals were removed from the aquarium before the nauplii were added and placed in an adjacent tank overnight, while fed corals remained in the experimental aquarium containing nauplii. Any nauplii remaining in the experimental aquarium the next morning were removed by filtration before the starved nubbins were returned. 
Pieces of fed and starved corals, including controls shielded from UVR by a Lee 226 polycarbonate filter, were taken periodically for the measurement of protein, chlorophyll $a$, and MAAs, as described by Shick (2004) and in subsection 'Biochemical measurements' below. Extracted skeletons subsequently were rinsed in distilled water, dried at $60^{\circ} \mathrm{C}$ for $3 \mathrm{~d}$, and weighed. The MAAs in nauplii were measured to allow a comparison of MAA-mass balance in fed and starved specimens of Stylophora pistillata.

Effects of ammonium enrichment on levels of protein, chlorophyll a, zooxanthellae, and MAAs. Nubbins from 2 distinguishable colonies Stylophora pistillata (SP1 and SP2) were maintained under PAR + UVR (irradiances given in previous subsection 'Experimental aquarium') without feeding for 15 and $30 \mathrm{~d}$. These included control specimens for each colony kept in the flowing seawater that normally supplies the maintenance and experimental aquaria, where the ambient concentration of ammonium was $<0.4 \mu \mathrm{M}$. Experimental colonies were exposed to a steady-state, enriched concentration of $\approx 10 \mu \mathrm{M}$ ammonium, achieved by adding a stock solution of $\mathrm{NH}_{4} \mathrm{Cl}$ in $0.45 \mu \mathrm{m}$ filtered seawater from a large batch tank. This stock solution was changed every day. It was continuously pumped from the batch tank to the aquarium using a peristaltic pump. The flow rate was $\approx 100 \mathrm{ml} \mathrm{min}^{-1}$ in order to avoid ammonium depletion in the aquarium. Ammonium concentrations were checked regularly using a nutrient autoanalyzer (Alliance Instruments). They remained stable in the aquarium during the whole experiment, varying between 9.0 and $10.5 \mu \mathrm{M}$. Coral nubbins were taken on Days 0, 15 and 30 for determination of MAAs, number of zooxanthellae, protein, and chlorophyll a per $\mathrm{cm}^{2}$ of colony surface area, as described in Grover et al. (2002), Shick (2004), and subsection 'Biochemical measurements' below.

Effect of UVR alone on accumulation of MAAs. The effects of PAR + UVR and of UVR alone on the accumulation of MAAs by Stylophora pistillata were tested by using Schott UG11 filters $(5.08 \times 5.08 \times 0.1 \mathrm{~cm})$, which transmit only wavelengths $<400 \mathrm{~nm}$ (and, to a smaller extent, those $>650 \mathrm{~nm}$ ). The filters were placed on PVC holders that covered $250 \mathrm{ml}$ opaque beakers in which nubbins were supported on nylon mesh above continuously operating magnetic stirrers. The distance between the beakers and the UV lamps was adjusted to compensate for the $\approx 10 \%$ attenuation of UVR by the UG11 filters. Inside the beakers without filters, measured irradiances were PAR $=210 \mu \mathrm{mol}$ photons $\mathrm{m}^{-2} \mathrm{~s}^{-1}$ $\left(\approx 46 \mathrm{~W} \mathrm{~m}^{-2}\right), \mathrm{UV}-\mathrm{A}=4.7 \mathrm{~W} \mathrm{~m}^{-2}$ and UV-B $=0.045$ to $0.051 \mathrm{~W} \mathrm{~m}^{-2}$. In beakers fitted with UG11 filters, PAR $(>650 \mathrm{~nm})=0.5$ to $0.6 \mu \mathrm{mol}$ photons $\mathrm{m}^{-2} \mathrm{~s}^{-1}(\approx 0.09$ to $0.10 \mathrm{~W} \mathrm{~m}^{-2}$ at $\left.680 \mathrm{~nm}\right) ; \mathrm{UV}-\mathrm{A}=4.6 \mathrm{~W} \mathrm{~m}^{-2}$, and UV-B $=$ 0.048 to $0.050 \mathrm{~W} \mathrm{~m}^{-2}$. Exposure was for $12 \mathrm{~h} \mathrm{~d}^{-1}$ for $6 \mathrm{~d}$.
In a subsequent experiment, nubbins were held in the experimental aquarium under the usual levels of PAR + UVR for $14 \mathrm{~d}$, with twice-weekly feeding, to ensure the synthesis of near-maximal concentrations of primary MAAs (Shick 2004). Then the nubbins were placed in individual beakers without filters covered with UV-transparent film (exposure to PAR + UVR), in beakers with Lee 226 filters (exposure to PAR only), or in beakers with UG11 filters (exposure to UVR only). Corals were not fed during the additional $7 \mathrm{~d}$ of such exposure in the beakers.

Effect of DCMU on accumulation of MAAs. This experiment was conducted in $250 \mathrm{ml}$ beakers containing $125 \mathrm{ml}$ of filtered seawater, to which was added either $0.1 \mathrm{ml}$ of ethanol (control), or $0.1 \mathrm{ml}$ of ethanolic stock solutions of dichlorophenyldimethyl urea (DCMU) to give final nominal concentrations of $10^{-4}$ or $10^{-5} \mathrm{M}$ of this inhibitor of Photosystem II. The seawater and the additives were renewed daily, and the nubbins were rotated among washed beakers daily. Recently fed nubbins were placed on nylon mesh above magnetic stirrers that operated continuously and were exposed to full PAR + UVR in both the control and DCMUexposed conditions. Nubbins were not fed after the start of the experimental conditions.

Experiments involving cultures of zooxanthellae from Stylophora pistillata. Because we were not successful in culturing zooxanthellae from those colonies of Red Sea $S$. pistillata that we studied, we used clonal cultures of zooxanthellae (Clade A1: LaJeunesse 2001) originally isolated by Banaszak et al. (2000) from a Red Sea colony of $S$. pistillata. These were maintained in $250 \mathrm{ml}$ screw-top polycarbonate Erlenmeyer flasks (Corning ${ }^{\circledR}$ ) in modified ASP-8A medium (Blank 1987) at $\mathrm{pH}$ 8.2. The zooxanthellae were grown in an incubator at $26 \pm 1^{\circ} \mathrm{C}$ under a PAR irradiance of $150 \mu \mathrm{mol}$ quanta $\mathrm{m}^{-2} \mathrm{~s}^{-1}\left(\sim 33 \mathrm{~W} \mathrm{~m}^{-2}\right)$ from Sylvania Gro Lux ${ }^{\circledR}$ and daylight fluorescent tubes, on a 12:12 h (light:dark) photoperiod. The stock cultures were transferred monthly. Cells were used in stationary phase. Experimental cultures were established by transferring stationary-phase cells into $25 \mathrm{ml}$ of fresh medium in $100 \mathrm{ml}$ beakers, which were then covered with UVtransparent film and the zooxanthellae maintained for $14 \mathrm{~d}$ under the foregoing conditions prior to the start of an experiment. During experiments the covered beakers (in the experimental aquarium) were exposed to the prevailing levels of PAR + UVR, or shielded from UVR by a Lee 226 polycarbonate filter.

To test whether a signal emanating from the host coral ('host factor') would stimulate qualitative or quantitative differences in MAA biosynthesis in $\mathrm{CZ}$ from Stylophora pistillata, pieces of 6 different colonies of $S$. pistillata (to include whatever genetic variation was present among these colonies) were exposed to 
PAR + UVR to induce MAA biosynthesis. Coral tissues (approximately $200 \mathrm{~cm}^{2}$ total area) were then removed with a Water-Pik, and the zooxanthellae were centrifuged $(1000 \times g$ for $10 \mathrm{~min})$ and pelleted from the resulting suspension and kept for analysis (see below, and subsection 'Biochemical measurements'). The host homogenate $(100 \mathrm{ml})$ was then centrifuged at $11000 \times g$ for 10 min to sediment tissue fragments and bacteria, sonicated for $10 \mathrm{~s}$, filtered $(0.22 \mu \mathrm{m})$, and aliquots of this filtered host tissue extract were frozen at $-80^{\circ} \mathrm{C}$.

Fresh cultures of zooxanthellae were grown for $28 \mathrm{~d}$ to achieve stationary phase (to approximate their growth rate in hospite: Falkowski et al. 1993) prior to being exposed to PAR + UVR in beakers in the experimental aquarium. Host tissue extract $(100 \mu \mathrm{l}$, determined in preliminary experiments) was added to UVexposed cultures $(25 \mathrm{ml})$ of zooxanthellae on Days 0 and 7 during a total of $14 \mathrm{~d}$ of exposure to PAR + UVR. $\mathrm{CZ}$ in this and other experiments were harvested onto glass fiber filters using gentle suction and immediately extracted in $80 \%$ HPLC-grade methanol, with sonic disruption for $3 \times 10 \mathrm{~s}$. Culture media from which zooxanthellae had been removed in the 'host factor' experiment were frozen at $-80^{\circ} \mathrm{C}$, lyophilized, and returned to Orono for analysis of MAAs.

The method of Goiran et al. (1996), with minor modifications, was used to clean the zooxanthellae freshly isolated from Stylophora pistillata prior to analyzing them for MAAs. The tissue slurry from UV-exposed corals was filtered through $200 \mu \mathrm{m}$ nylon mesh and centrifuged at $750 \times g$ for $5 \mathrm{~min}$ at $4^{\circ} \mathrm{C}$. The pellet was resuspended in Millipore-filtered $(0.22 \mu \mathrm{m})$ seawater and centrifuged 5 times at $750 \times g$, each time in a large volume of filtered seawater, to prepare zooxanthellae free of visible microscopic contamination. The zooxanthellae were sedimented by a final gentle centrifugation and extracted immediately in $80 \%$ HPLC-grade methanol, with sonication.

Biochemical measurements. Living corals and brine shrimps were extracted in 100\% HPLC-grade methanol and analyzed for MAAs as described in Shick (2004). Chlorophyll $a$ in the methanolic extracts of corals and zooxanthellae $(80 \% \mathrm{MeOH})$ prior to cleaning on Waters C-18 Sep-Pak Plus cartridges was quantified spectrophotometrically using the extinction coefficient of $0.0191 \mathrm{~m}^{2}\left(\mathrm{mg}\right.$ chlorophyll a) ${ }^{-1}$ at $665 \mathrm{~nm}$ in $95 \%$ methanol (Stramski \& Morel 1990). This was checked on a subset of coral samples analyzed by quantitative HPLC (J. Ras, Laboratoire d'Océanographie de Villefranche, pers. comm.). Protein in methanolextracted colonies was solubilized and analyzed as in Grover et al. (2002). Lyophilized zooxanthella culture media were rehydrated and analyzed for MAAs by injection directly onto a Waters HPLC system (Shick et al. 1999) with a Phenosphere amino column (4.6 mm inner diameter $\times 250 \mathrm{~mm}$ ) and amino guard column (Phenomenex), in a mobile phase of $40 \mathrm{mM}$ ammonium acetate and $17.5 \mathrm{mM}$ acetic acid in $80 \%$ methanol (technique from W. C. Dunlap, Australian Institute of Marine Sciences, pers. comm.).

\section{RESULTS}

\section{Effect of feeding on accumulation of MAAs}

Starvation caused a decrease in protein concentration over time $\left(b=-0.161, \mathrm{r}^{2}=0.659, \mathrm{p}=0.002\right)$, whereas after a transient increase by Day 3, the protein concentration in fed colonies was stable throughout the experiment $\left(b=0.089, \mathrm{r}^{2}=0.164, \mathrm{p}=0.135\right)$

Table 1. Stylophora pistillata. Results of ANOVAs for effects of colony of origin (SP1 and SP2), treatment (ammonium enrichment), and time (duration of experiment, d) on levels of

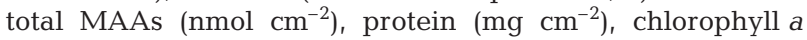
$\left(\mu \mathrm{g} \mathrm{cm}^{-2}\right)$, and zooxanthellae $\left(10^{6}\right.$ zooxanthellae $\left.\mathrm{cm}^{-2}\right) . \mathrm{NS}=$ not significant

\begin{tabular}{|c|c|c|c|}
\hline & $\mathrm{df}$ & $F$ & $\mathrm{p}$ \\
\hline \multicolumn{4}{|l|}{ nmol total MAAs $\mathrm{cm}^{-2}$} \\
\hline Colony & 1 & 11.231 & 0.017 \\
\hline Treatment & 1 & 1.281 & 0.2638 (NS) \\
\hline Time (day) & 2 & 216.643 & $<0.001$ \\
\hline Colony $\times$ Treatment & 1 & 11.371 & 0.0016 \\
\hline Colony $\times$ Time & 2 & 3.460 & 0.0402 \\
\hline Treatment $\times$ Time & 2 & 0.542 & 0.5857 (NS) \\
\hline Colony $\times$ Treatment $\times$ Time & 2 & 6.421 & 0.0036 \\
\hline Error & 44 & & \\
\hline \multicolumn{4}{|l|}{ mg protein $\mathrm{cm}^{-2}$} \\
\hline Colony & 1 & 1.735 & 0.1946 (NS) \\
\hline Treatment & 1 & 0.025 & 0.8752 (NS) \\
\hline Time (day) & 2 & 46.310 & $<0.001$ \\
\hline Colony $\times$ Treatment & 1 & 0.318 & 0.5760 (NS) \\
\hline Colony $\times$ Time & 2 & 2.913 & 0.0648 (NS) \\
\hline Treatment $\times$ Time & 2 & 4.878 & 0.0122 \\
\hline Colony $\times$ Treatment $\times$ Time & 2 & 0.257 & $0.7744(\mathrm{NS})$ \\
\hline Error & 44 & & \\
\hline \multicolumn{4}{|l|}{$\mu \mathrm{g}$ chlorophyll $\mathrm{a} \mathrm{cm}^{-2}$} \\
\hline Colony & 1 & 14.011 & 0.0005 \\
\hline Treatment & 1 & 27.646 & $<0.001$ \\
\hline Time (day) & 2 & 6.641 & 0.0030 \\
\hline Colony $\times$ Treatment & 1 & 0.330 & $0.5686(\mathrm{NS})$ \\
\hline Colony $\times$ Time & 2 & 0.108 & $0.8983(\mathrm{NS})$ \\
\hline Treatment $\times$ Time & 2 & 6.600 & 0.0031 \\
\hline Colony $\times$ Treatment $\times$ Time & 2 & 0.229 & $0.7960(\mathrm{NS})$ \\
\hline Error & 44 & & \\
\hline \multicolumn{4}{|l|}{$10^{6}$ zooxanthellae $\mathrm{cm}^{-2}$} \\
\hline Colony & 1 & 0.493 & 0.4891 (NS) \\
\hline Treatment & 1 & 1.632 & $0.2136 \mathrm{NS})$ \\
\hline Time (day) & 2 & 7.215 & 0.0035 \\
\hline Colony $\times$ Treatment & 2 & 0.437 & $0.5147(\mathrm{NS})$ \\
\hline Colony $\times$ Time & 2 & 6.125 & 0.0071 \\
\hline Treatment $\times$ Time & 2 & 0.961 & $0.3969(\mathrm{NS})$ \\
\hline Colony $\times$ Treatment $\times$ Time & 2 & 0.117 & 0.8905 (NS) \\
\hline
\end{tabular}



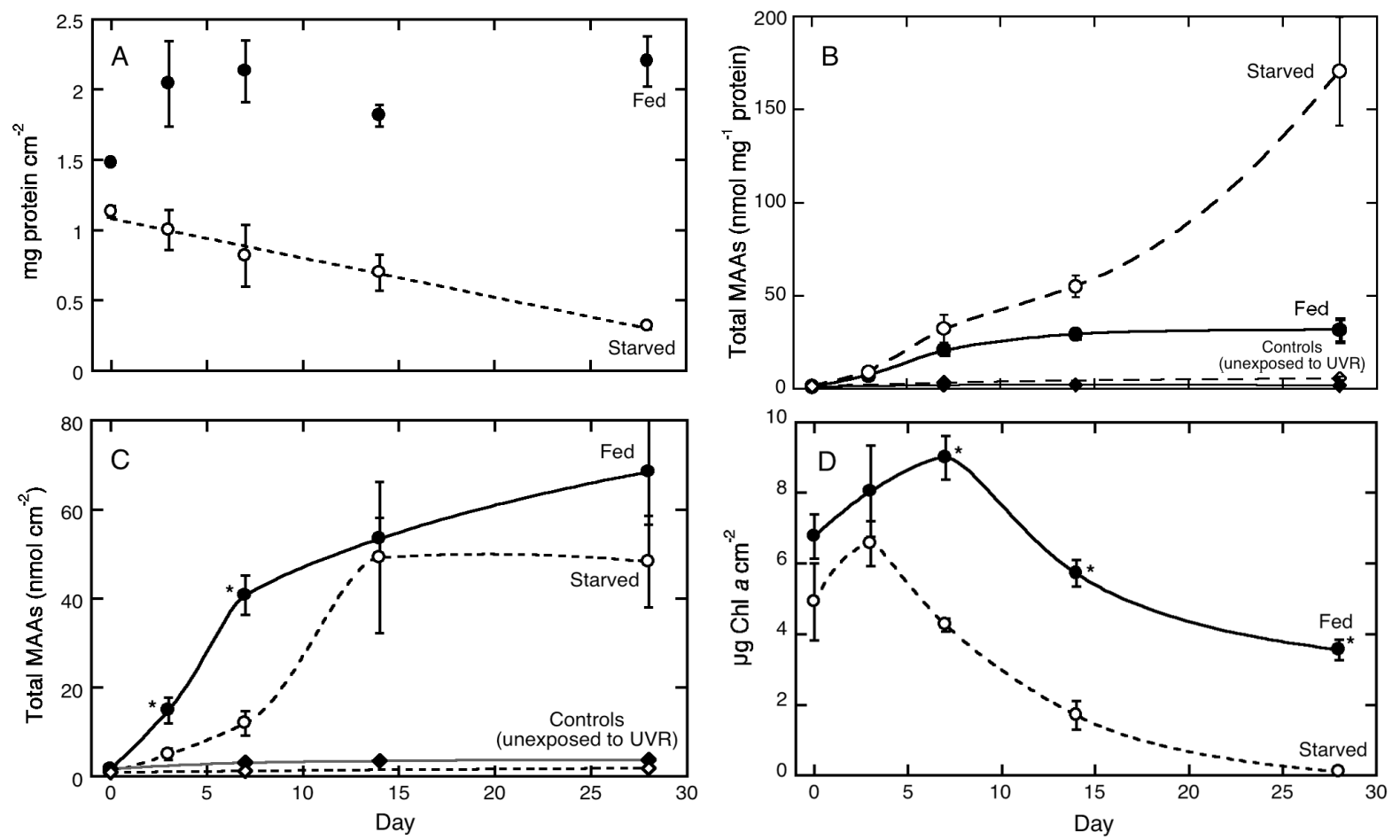

Fig. 1. Stylophora pistillata. Effects of feeding and starvation on (A) mg protein $\mathrm{cm}^{-2}$ of colony surface area, (B) nmol total MAAs $\mathrm{mg}^{-1}$ protein, (C) nmol total MAAs $\mathrm{cm}^{-2}$, and (D) $\mu \mathrm{g}$ chlorophyll $\mathrm{a} \mathrm{cm}^{-2}$ in nubbins exposed to PAR + UVR, and MAAs in control nubbins unexposed to UVR (B and C). Data for fed corals are represented by closed symbols and solid line; starved corals indicated by open symbols and broken line. Data are mean $\pm \mathrm{SE}, \mathrm{n}=3$. If error bars are not visible, they are smaller than the size of the symbol. Asterisks (*) indicate significant differences in MAAs cm${ }^{-2}$ and chlorophyll $\mathrm{cm}^{-2}$ between fed and starved colonies on a given day (SNK tests, $\mathrm{p}<0.05$ )

(Fig. 1A). A 2-way ANOVA indicated a significant effect of feeding status $(F=126.29$, df $=1, \mathrm{p}<0.0001)$, no effect of time (days; $F=2.92, \mathrm{df}=4, \mathrm{p}=0.399$ ), and a significant interaction between feeding status and time $(F=5.96$, df $=4, \mathrm{p}<0.0025)$ on protein concentration $\mathrm{g}^{-1}$ of dry skeleton. Therefore, MAAs expressed per mg protein (Fig. 1B) cannot meaningfully be compared between the 2 groups, nor is MAA mg ${ }^{-1}$ protein a useful measure of MAA accumulation in starved corals.

Because starvation of corals does not cause a loss of calcified skeleton (Franzisket 1970), biochemical measures were normalized to skeletal mass (Edmunds \& Gates 2002) to enable comparisons between fed and starved corals. In the standard-size nubbins used in these experiments, skeletal mass (dry weight, g) itself is predictably related to a more commonly used parameter, colony surface area $\left(\mathrm{S}, \mathrm{cm}^{2}\right)$, where $\mathrm{S}=4.653 \times$ (dry weight $)+1.225\left(\mathrm{n}=10, \mathrm{r}^{2}=0.992\right)$. Therefore, biochemical measures are expressed per $\mathrm{cm}^{2}$ of colony surface area (Fig. 1C). We cannot explain the initial difference in colony protein in the experimental nubbins (Fig. 1A), which were randomly chosen from the stocks in the maintenance aquarium; regardless of the initial difference, the treatments clearly had different effects on protein.
A 2-way ANOVA also indicated significant temporal changes in chlorophyll a $\mathrm{cm}^{-2}$ in fed and starved corals (Fig. 1D). Starvation resulted in a faster loss of chlorophyll $a$, so that between Days 0 and 28, chlorophyll a $\mathrm{cm}^{-2}$ had fallen by $47 \%$ in fed colonies but by $98 \%$ in starved corals. The decline started sooner (after Day 3) in starved colonies than in fed nubbins (after Day 7).

The concentrations of total MAAs $\mathrm{cm}^{-2}$ in control colonies exposed to PAR but shielded from UVR did not differ with feeding status or time (Fig. 1C). Starved colonies exposed to PAR + UVR lagged behind fed colonies in initiating MAA accumulation up to Day 7 , when the difference was greatest, and by which time chlorophyll a had already started to decline in starved but not in fed nubbins. A 2-way ANOVA and StudentNewman-Keuls (SNK) tests indicated that, by Day 28, there was no difference between fed and starved colonies in their total MAAs $\mathrm{cm}^{-2}$, most of which were accumulated by Day 14 (Fig. 1C).

Freshly hatched nauplii of Artemia sp. (Utah B2005 strain) contained only 1 MAA, mycosporine-2 glycine, at a concentration of $0.08 \mathrm{nmol} \mathrm{g}^{-1}$ wet weight. This MAA has not heretofore been reported in brine shrimps (cf. Grant et al. 1985). 


\section{Effects of ammonium enrichment on levels of protein, chlorophyll $a$, zooxanthellae, and MAAs}

Total concentration of MAAs differed significantly between the colonies, with $\sim 40 \%$ higher concentration being achieved in control nubbins of colony SP2 compared with SP1; total MAAs varied with time but not with treatment, although the latter was owing to a significant interaction between treatment and colony, and a 3-way interaction among treatment, colony, and time, in total MAAs (Table 1, Fig. 2A,C). There was no significant effect of colony of origin, or of treatment, on protein $\mathrm{cm}^{-2}$, but there was a significant effect of time on this parameter (Table 1, Fig 2A,C), so MAA concentrations in Figs. 2 to 5 are expressed per $\mathrm{cm}^{2}$ of colony surface area and not per mg protein. Time had a significant primary effect on the number of zooxanthellae $\mathrm{cm}^{-2}$, and there was also a significant interaction between colony and time on this parameter (Table 1, Fig. 2B,D). The concentration of chlorophyll a per $\mathrm{cm}^{2}$ varied significantly with colony of origin, treatment, and time, and also showed a significant interaction between treatment and time (Table 1, Fig. 2B,D).

Analyses of individual MAAs were likewise complex, and the results are summarized in Figs. $3 \& 4$.
The effects of colony and treatment on pooled primary and secondary MAAs are shown in Fig. 5A,B. In addition to the $40 \%$ greater concentration of total MAAs achieved in control nubbins of colony SP2 compared with control nubbins of colony SP1 (Fig. 2A,C), immediately apparent was the absence from SP2 of mycosporine-2 glycine and palythine, which were predominant MAAs in SP1 (cf. Figs. $3 \& 4$ ). Also, the rate of accumulation of secondary MAAs in SP2 was about half that in SP1, although primary MAAs accumulated faster in SP2 (cf. Fig. 5A,B). Consequently, SP2 consistently had a larger proportion of primary MAAs than SP1.

The effects of ammonium enrichment were manifested largely in primary MAAs (but in opposite directions in SP1 and SP2), while secondary MAAs were little affected by ammonium level (Fig. 5A,B). Ammonium enrichment had a large effect on chlorophyll $a$ concentration but no significant effect on zooxanthella density (Fig. 2B,D), which decreased significantly with time in enriched and control nubbins of SP1 but not SP2 (Table 1). The extent to which known rates of ammonium uptake by starved colonies (Grover et al. 2002) can support the observed rates of MAA accumulation are calculated in Table 2 and considered in the 'Discussion' section.

Fig. 2. Stylophora pistillata. Colonies SP1 and SP2. Effects of ammonium enrichment on $(A, C)$ mg protein $\mathrm{cm}^{-2}(\triangle, \mathbf{\Lambda})$ and $\mathrm{nmol}$ total MAAs $\mathrm{cm}^{-2}$ $(\mathrm{O}, \bullet)$, and $(\mathrm{B}, \mathrm{D})$ number of zooxanthellae $\mathrm{cm}^{-2}(\mathrm{O}, \bullet)$ and $\mu \mathrm{g}$ chlorophyll $a_{\mathrm{cm}^{-2}}(\Delta, \mathbf{\Lambda})$. Open symbols and broken line are for starved corals not exposed to enriched ammonium concentrations (control), and solid symbols and solid line are for starved colonies exposed to $10 \mu \mathrm{M}$ $\mathrm{NH}_{4} \mathrm{Cl}$ in seawater, all during exposure to PAR + UVR starting on Day 0. Data are mean $\pm \mathrm{SE}, \mathrm{n}=3$ to 7 . Asterisks $(*)$ indicate significant difference between enriched and control nubbins on a given day (SNK tests, $p<0.05)$. Different lower-case letters $(a, b, c)$ denote significant differences (SNK tests, p < 0.05) among control nubbins on different days. Different Arabic numerals $(1,2)$ denote significant differences (SNK tests, $\mathrm{p}<0.05$ ) among enriched nubbins on different days
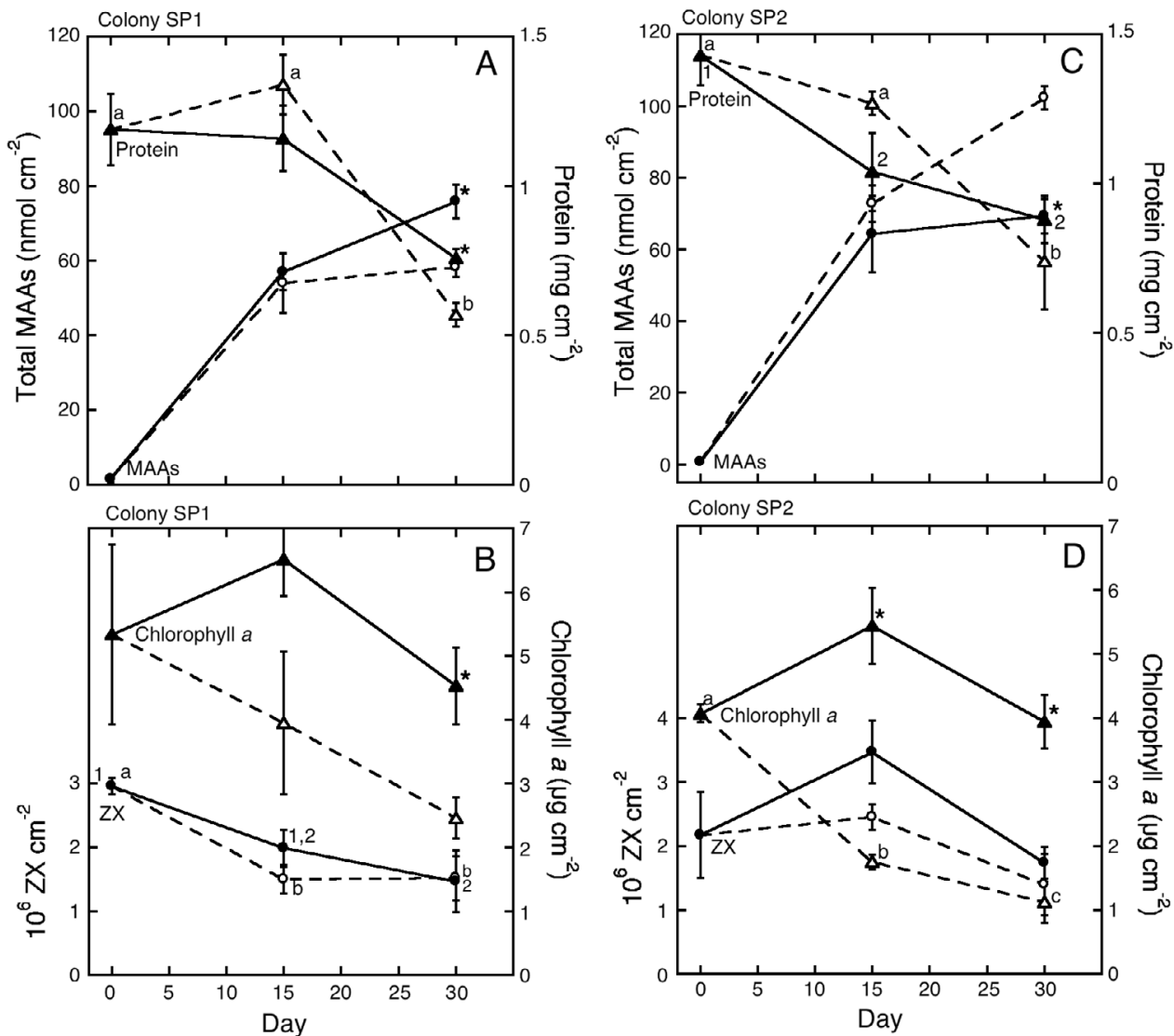

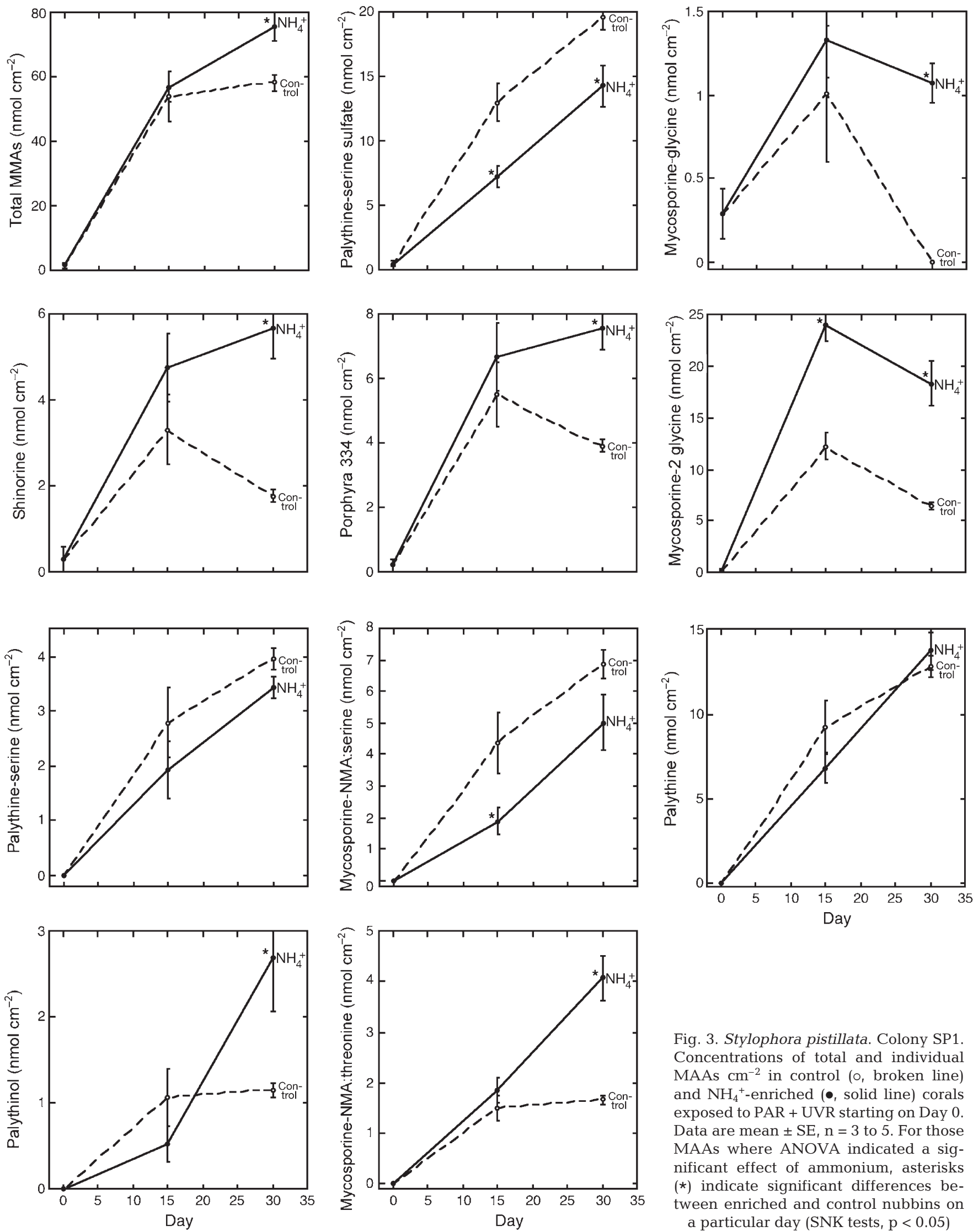

Fig. 3. Stylophora pistillata. Colony SP1. Concentrations of total and individual MAAs $\mathrm{cm}^{-2}$ in control (o, broken line) and $\mathrm{NH}_{4}{ }^{-}$-enriched $(\bullet$, solid line) corals exposed to PAR + UVR starting on Day 0. Data are mean $\pm \mathrm{SE}, \mathrm{n}=3$ to 5 . For those MAAs where ANOVA indicated a significant effect of ammonium, asterisks (*) indicate significant differences between enriched and control nubbins on a particular day (SNK tests, $\mathrm{p}<0.05$ ) 

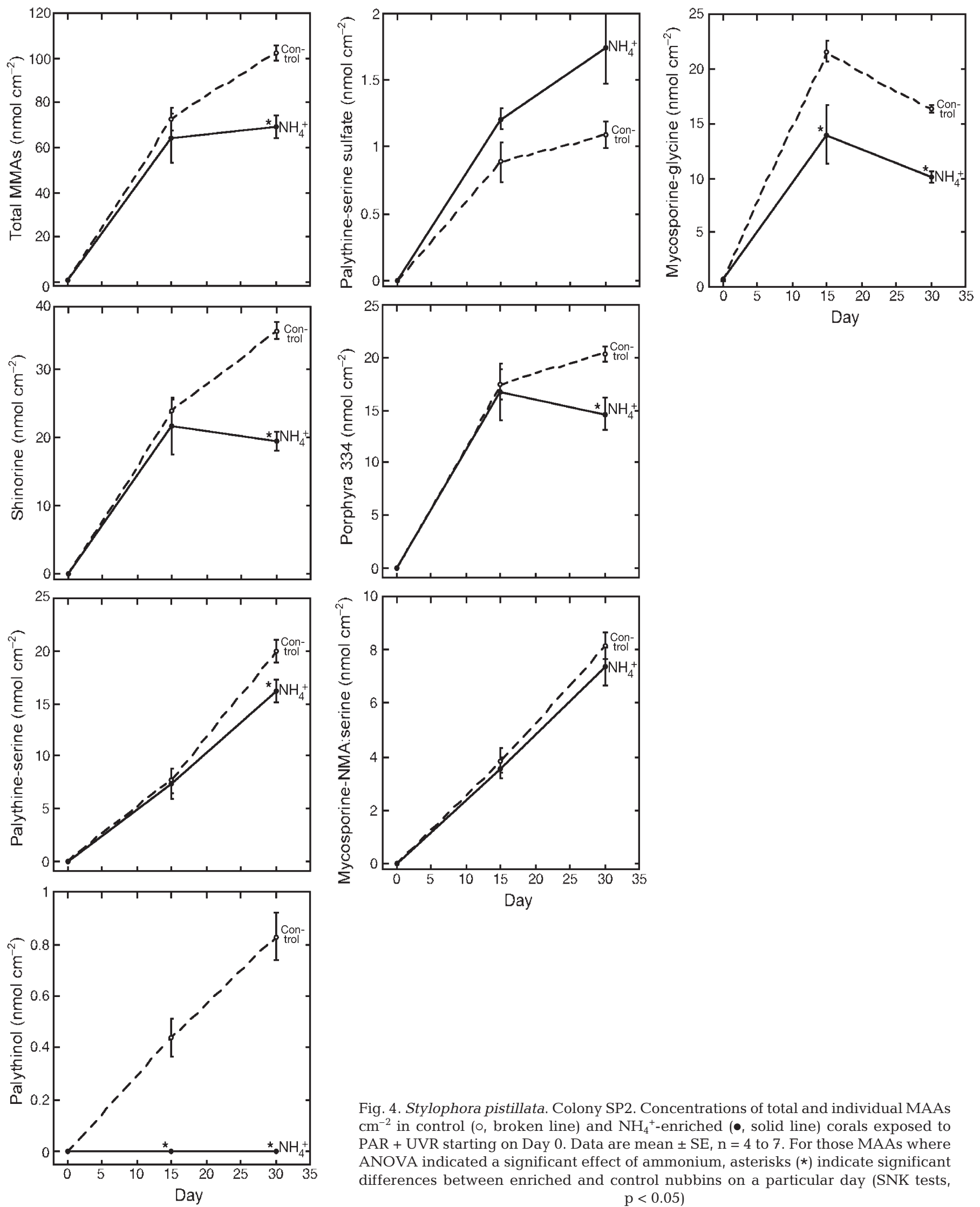

Fig. 4. Stylophora pistillata. Colony SP2. Concentrations of total and individual MAAs $\mathrm{Cm}^{-2}$ in control $\left(\mathrm{O}\right.$, broken line) and $\mathrm{NH}_{4}{ }^{+}$-enriched $(\bullet$, solid line) corals exposed to $\mathrm{PAR}+\mathrm{UVR}$ starting on Day 0. Data are mean $\pm \mathrm{SE}, \mathrm{n}=4$ to 7 . For those MAAs where ANOVA indicated a significant effect of ammonium, asterisks $(*)$ indicate significant differences between enriched and control nubbins on a particular day (SNK tests, $\mathrm{p}<0.05)$ 

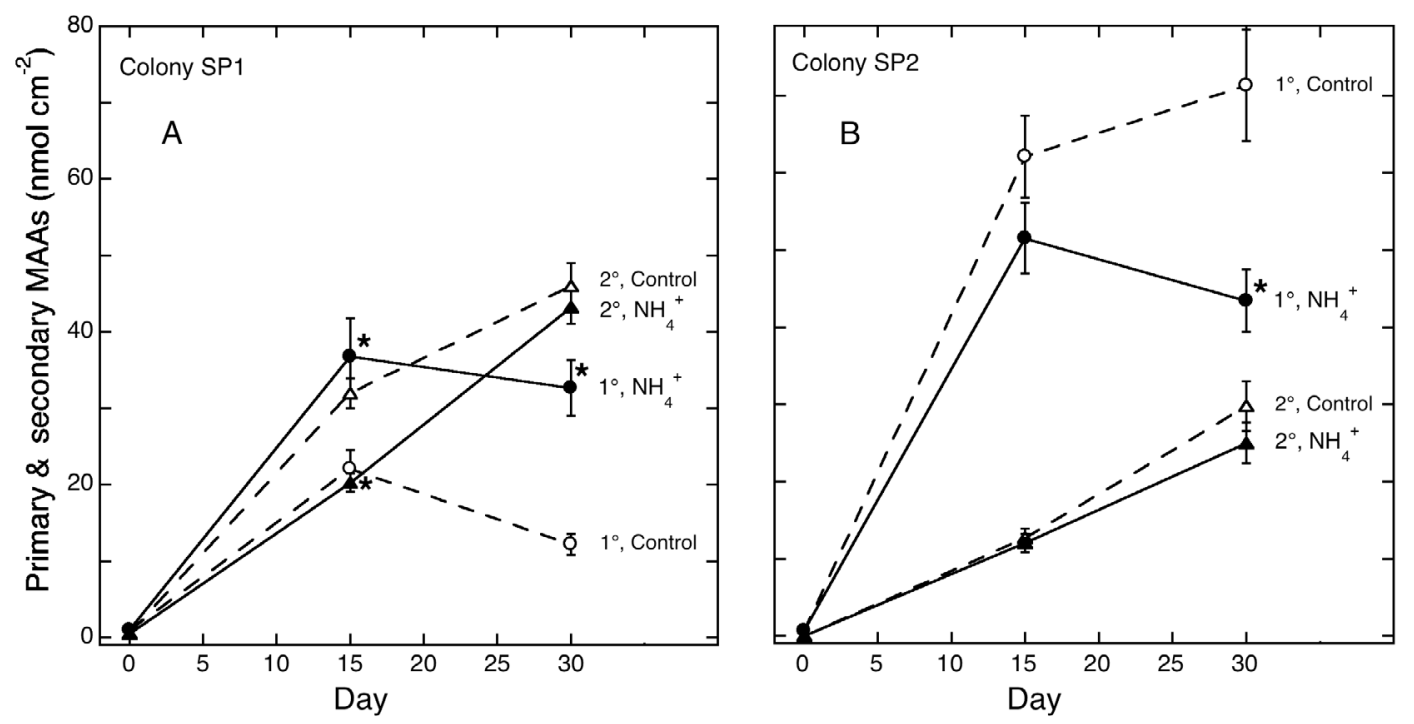

Fig. 5. Stylophora pistillata. Concentrations of primary $(0, \bullet)$ and secondary $(\triangle, \mathbf{\Lambda}) \mathrm{MAAs} \mathrm{cm}^{-2}$ in control (open symbols) and $\mathrm{NH}_{4}{ }^{+}$-enriched (solid symbols) nubbins of (A) Colony SP1 and (B) Colony SP2 exposed to PAR + UVR starting on Day 0. Data are mean $\pm \mathrm{SE}, \mathrm{n}=3$ to 7 . In cases where ANOVA indicated a significant effect of ammonium, asterisks ( , associated with the symbol for the $\mathrm{NH}_{4}{ }^{+}$-enriched nubbins) indicate significant differences between enriched and control nubbins on a particular day (SNK tests, $\mathrm{p}<0.05)$

\section{Effect of UVR alone on accumulation of MAAs}

In the first experiment, 9 MAAs were detected in nubbins exposed to PAR + UVR for $6 \mathrm{~d}, 6$ MAAs in those nubbins exposed to UVR only, and 1 MAA (palythine-serine sulfate) in nubbins previously exposed only to PAR and extracted on Day 0. ANOVA indicated a significant effect of treatment on total MAA concentration and on 7 of the 9 MAAs present (Table 3). Mean concentrations of total and individual MAAs were compared using SNK tests, or Kruskal-Wallis tests for those MAAs in which variances were inhomogeneous. Total MAA concentration, and concentrations of 7 MAAs, were significantly higher in nubbins exposed to PAR + UVR than they were in Day 0 nubbins, and the concentrations of total and 5 individual MAAs were greater in nubbins exposed to PAR + UVR than in those exposed to UVR only. Total MAAs were more concentrated in colonies exposed to UVR only than in Day 0

Table 2. Stylophora pistillata. Uptake of ammonium-nitrogen and accumulation of MAA-nitrogen in Colonies SP1 and SP2 during (A) Days 0 to 15 and (B) Days 15 to 30 of starvation. Rates of ammonium uptake are calculated (assuming linearity of diffusive uptake with concentration up to $20 \mu \mathrm{M}$ ) from data in Grover et al. (2002) for unfed colonies, which absorb $\mathrm{NH}_{4}{ }^{+}$in the light and at night, under conditions similar to those in the present study. Control colonies exposed to ambient $\mathrm{NH}_{4}{ }^{+}$at $0.4 \mu \mathrm{M}$ absorb $1.4 \mathrm{nmol}$ $\mathrm{N} \mathrm{cm}^{-2} \mathrm{~h}^{-1} ; \mathrm{NH}_{4}^{+}$-enriched corals at $10 \mu \mathrm{M}$ absorb $35.7 \mathrm{nmol} \mathrm{N} \mathrm{cm}^{-2} \mathrm{~h}^{-1}$

\begin{tabular}{|c|c|c|c|c|c|c|c|}
\hline & & $\begin{array}{l}\text { MAA conc., } \\
\text { Day 0 } \\
\left(\mathrm{nmol} \mathrm{cm}^{-2}\right)\end{array}$ & $\begin{array}{l}\text { MAA conc., } \\
\text { Day } 15 \\
\left(\mathrm{nmol} \mathrm{cm}^{-2}\right)\end{array}$ & $\begin{array}{c}\text { Net MAA } \\
\text { accumulation } \\
\left(\mathrm{nmol} \mathrm{cm}^{-2} 15 \mathrm{~d}^{-1}\right)\end{array}$ & $\begin{array}{c}\text { Net MAA-N } \\
\text { accumulation } \\
\left(\mathrm{nmol} \mathrm{N} \mathrm{cm}^{-2} 15 \mathrm{~d}^{-1}\right)\end{array}$ & $\begin{array}{c}\text { Cumulative } \\
\mathrm{NH}_{4}^{+}-\mathrm{N} \text { uptake } \\
\left(\mathrm{nmol} \mathrm{N} \mathrm{cm}^{-2} 15 \mathrm{~d}^{-1}\right)\end{array}$ & $\begin{array}{c}\text { Percent of } \\
\mathrm{NH}_{4}^{+}-\mathrm{N} \text { present } \\
\text { in MAAs }\end{array}$ \\
\hline \multirow[t]{6}{*}{ (A) } & Colony SP1 & & & & & & \\
\hline & Control & 1.5 & 54 & 52.5 & 104.3 & 514 & 20.3 \\
\hline & $+\mathrm{NH}_{4}{ }^{+}$ & 1.5 & 57 & 55.5 & 110.0 & 12850 & 0.9 \\
\hline & Colony SP2 & & & & & & \\
\hline & Control & 0.7 & 73 & 72.3 & 123.6 & 514 & 24.0 \\
\hline & $+\mathrm{NH}_{4}^{+}$ & 0.7 & 64 & 63.3 & 113.9 & 12850 & 0.9 \\
\hline \multirow[t]{6}{*}{ (B) } & Colony SP1 & & & & & & \\
\hline & Control & 54 & 58 & 4 & 7.0 & 514 & 1.4 \\
\hline & $+\mathrm{NH}_{4}^{+}$ & 57 & 75 & 18 & 35.8 & 12850 & 0.3 \\
\hline & Colony SP2 & & & & & & \\
\hline & Control & 73 & 102 & 29 & 53.1 & 514 & 10.3 \\
\hline & $+\mathrm{NH}_{4}{ }^{+}$ & 64 & 69 & 5 & 6.2 & 12850 & $<0.1$ \\
\hline
\end{tabular}


nubbins, primarily because of increases in mycosporine-2 glycine and palythine.

Mycosporine-glycine (undetectable on Day 0) and other MAAs low in concentration were more reliably quantified in corals experiencing a longer (14 d) exposure to full PAR + UVR prior to their placement under different spectral conditions in the beakers. ANOVA indicated no net accumulation of total MAAs after the start of different spectral conditions on Day 14 in any treatment (Fig. 6). Mycosporine-2 glycine and mycosporine-glycine remained at their same concentrations as at Day 14 if maintained under PAR + UVR for an additional $7 \mathrm{~d}$ (Fig. 6). Like 2 other primary MAAs (shinorine and porphyra-334), they decreased in concentration after Day 14 if the corals were given only PAR or only UVR (Fig. 6).

None of the secondary MAAs showed a significant change under any condition after Day 14 (ANOVA, $\mathrm{p}>0.05$ in all cases), except for palythine-serine sulfate, which increased if PAR was present, and (equivocally) under UVR alone (SNK test results, Fig. 6). Failure of the other secondary MAAs to increase in the 2 treatments in which PAR was present may reflect the shorter time available for such changes to occur (an additional $7 \mathrm{~d}$ here vs $14 \mathrm{~d}$ in the earlier experiments); all secondary MAAs con- sistently tended to increase under these conditions, albeit not significantly (data not shown).

\section{Effect of DCMU on accumulation of MAAs}

Corals exposed to $10^{-4} \mathrm{M}$ DCMU died within 2 to $3 \mathrm{~d}$, and those exposed to $10^{-5} \mathrm{M}$ DCMU began to appear unhealthy on Day 5 , when the experiment was prematurely terminated. Compared with control nubbins, those exposed to $10^{-5}$ DCMU showed no change in the concentration of chlorophyll $\mathrm{a} \mathrm{cm}^{-2}$ of colony surface area (data not shown; $t=1.516, \mathrm{df}=6, \mathrm{p}=0.180$ ). The amount of protein $\mathrm{cm}^{-2}$ (data not shown) declined significantly by $46 \%$ in DCMU-treated nubbins $(t=3.229, \mathrm{df}=6$, $p=0.018$ ); therefore, MAA concentrations (Fig. 7) are expressed per $\mathrm{cm}^{2}$. As usual, the enigmatic palythine-serine sulfate was present in nubbins at the start of the experiment (data not shown) and did not differ between control and DCMU-treated nubbins $(t=0.473, \mathrm{df}=6$, $\mathrm{p}=0.653$ ). Discounting palythine-serine sulfate, the accumulation of total MAAs was $62 \%$ higher in control nubbins than in those exposed to DCMU, owing to greater increases in the primary MAAs mycosporineglycine, shinorine, and mycosporine-2 glycine (Fig. 7).
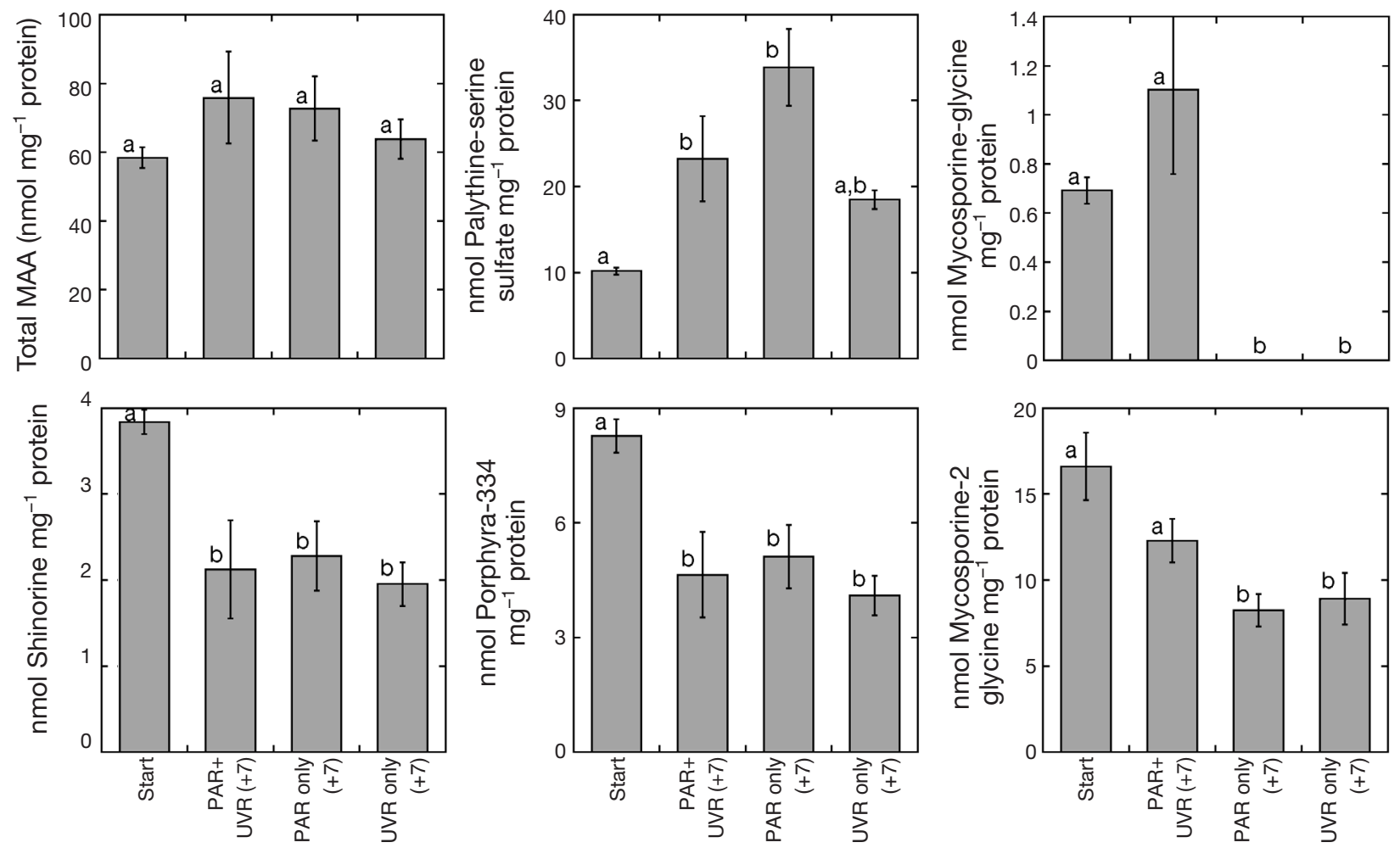

Fig. 6. Stylophora pistillata. Concentrations of total MAAs (which did not vary significantly among treatments: ANOVA, $p>0.05$ ) and of those individual MAAs that did vary significantly $(p<0.05)$ in nubbins after $14 \mathrm{~d}$ of exposure to PAR + UVR in the experimental aquarium ('Start' of varied spectral treatments), and in nubbins receiving PAR + UVR, PAR only, or UVR only for an additional $7 \mathrm{~d}$. Data are mean $\pm \mathrm{SE}, \mathrm{n}=3$ or 4 . For each MAA, means that are significantly different (SNK tests, $\mathrm{p}<0.05)$ have different lower-case letters $(a, b)$ 
Table 3. Stylophora pistillata. Results of ANOVA for nubbins at the start of the experiment (Day 0), and after $6 \mathrm{~d}$ of exposure to UVR only or to PAR + UVR. Mean concentrations $( \pm \mathrm{SE} ; \mathrm{n}=4)$ of total and individual MAAs (nmol MAA mg ${ }^{-1} \mathrm{protein}$ are given for each treatment. Superscripted letters present the results of Student-Newman-Keuls (SNK) multiple-comparison tests among treatments for each MAA where the ANOVA indicated a significant effect of treatment; means that are not significantly different ( $p>0.05)$ have the same superscript. Variances for mycosporine-2 glycine and palythine mean concentrations were not homogeneous $(p<0.001$ and $p=0.026$, respectively), so the data were compared using the non-parametric Kruskal-Wallis rank sums and pairwise

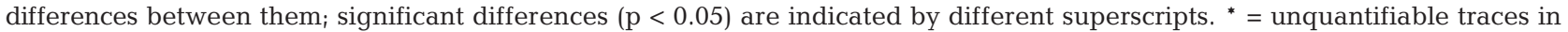
some specimens. NS = not significant

\begin{tabular}{|llllll|}
\hline \multirow{2}{*}{ MAA } & \multicolumn{2}{c}{} & & \multicolumn{2}{c|}{ Treatment } \\
\cline { 3 - 6 } & \multicolumn{2}{c}{ ANOVA } & Day 0 & UV only & PAR + UVR \\
\hline Total & $F_{2,9}=38.55$ & $\mathrm{p}<0.001$ & $3.48^{\mathrm{a}}(0.36)$ & $6.97^{\mathrm{b}}(0.71)$ & $13.96^{\mathrm{c}}(1.26)$ \\
Palythine-serine sulfate & $F_{2,9}=2.37$ & $\mathrm{p}=0.149(\mathrm{NS})$ & $3.48(0.36)$ & $4.72(0.69)$ & $4.83(0.33)$ \\
Mycosporine-glycine & $F_{2,9}=1037.81$ & $\mathrm{p}<0.001$ & $0.00^{\mathrm{a}}(0.00)$ & $0.00^{\mathrm{a} *}(0.00)$ & $0.66^{\mathrm{b}}(0.02)$ \\
Shinorine & $F_{2,9}=14.81$ & $\mathrm{p}=0.001$ & $0.00^{\mathrm{a}}(0.00)$ & $0.00^{\mathrm{a}}(0.00)$ & $0.32^{\mathrm{b}}(0.08)$ \\
Porphyra-334 & $F_{2,9}=8.42$ & $\mathrm{p}=0.009$ & $0.00^{\mathrm{a}}(0.00)$ & $0.00^{\mathrm{a}}(0.00)$ & $0.38^{\mathrm{b}}(0.13)$ \\
Mycosporine-2 glycine & $F_{2,9}=26.25$ & $\mathrm{p}<0.001$ & $0.00^{\mathrm{a}}(0.00)$ & $1.71^{\mathrm{b}}(0.04)$ & $6.50^{\mathrm{c}}(1.14)$ \\
Palythine-serine & $F_{2,9}=2.81$ & $\mathrm{p}=0.112(\mathrm{NS})$ & $0.00(0.00)$ & $0.00(0.00)$ & $0.06(0.03)$ \\
Mycosporine-NMA:serine & $F_{2,9}=7.43$ & $\mathrm{p}=0.013$ & $0.00^{\mathrm{a}}(0.00)$ & $0.05^{\mathrm{b}}(0.01)$ & $0.07^{\mathrm{b}}(0.02)$ \\
Palythine & $F_{2,9}=43.57$ & $\mathrm{p}<0.001$ & $0.00^{\mathrm{a}}(0.00)$ & $0.45^{\mathrm{b}}(0.03)$ & $1.10^{\mathrm{c}}(0.14)$ \\
Mycosporine-NMA:threonine & $F_{2,9}=6.44$ & $\mathrm{p}=0.018$ & $0.00^{\mathrm{a}}(0.00)$ & $0.04^{\mathrm{b}}(0.01)$ & $0.05^{\mathrm{b}}(0.02)$ \\
\hline
\end{tabular}

\section{Experiments involving cultures of zooxanthellae from Stylophora pistillata}

Stock cultures (unexposed to UVR) of zooxanthellae originally isolated from Stylophora pistillata contained low levels of both shinorine and mycosporine-glycine

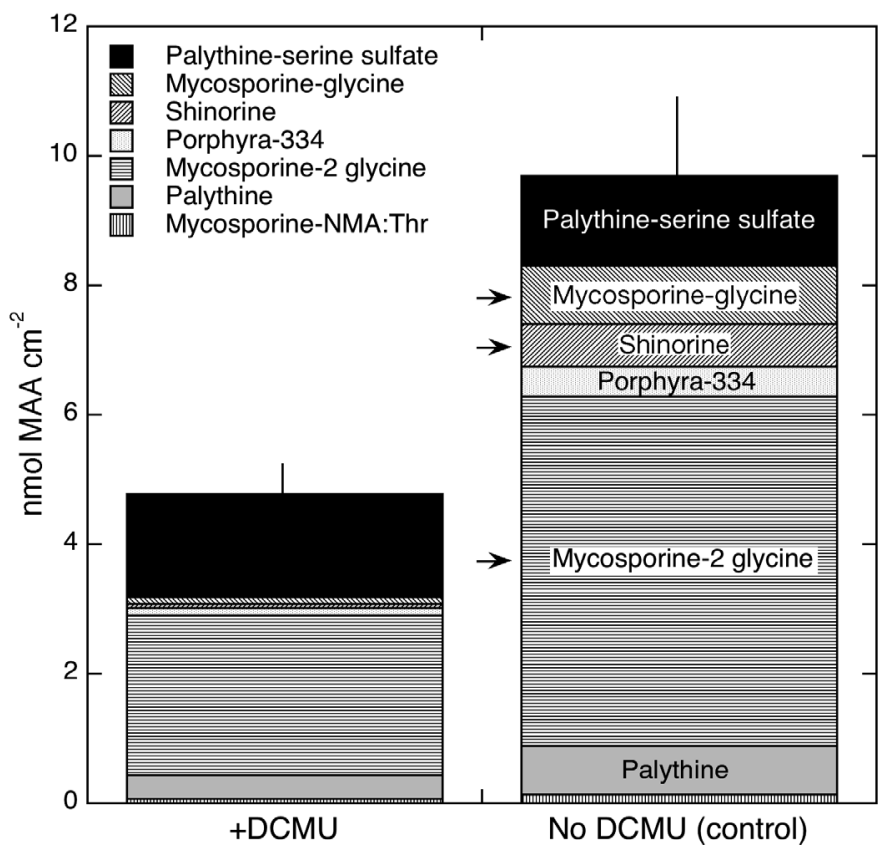

Fig. 7. Stylophora pistillata. Effects of $10^{-5} \mathrm{M}$ DCMU on the accumulation of MAAs in corals exposed to PAR +UVR for $5 \mathrm{~d}$. Arrows indicate individual MAAs whose concentration in nubbins unexposed to DCMU were significantly different from those in DCMU-treated nubbins $(t$-tests, $\mathrm{df}=6, \mathrm{p}<0.05)$. Vertical lines indicate SE for mean total concentration of MAAs
(Fig. 8A,B). The latter MAA was not found in this isolate by Banaszak et al. (2000), perhaps owing to its extremely low concentration. In one experiment (Fig. 8A), growing cultures responded to UVR with a linear increase in the concentration of shinorine. In a second experiment (Fig. 8B), there was no direct relationship between the cumulative UV dose and the concentration of either MAA; in that experiment, both MAAs showed a transient increase followed by a decline.

Results of the Stylophora pistillata 'host factor' experiment are shown in Fig. 9. CZ at the start of the experiment were in stationary phase and contained lower concentrations of shinorine than did stock cultures that were growing (cf. Figs. 8 \& 9). Traces of mycosporine-glycine were present in stationary-phase cultures. The concentration of shinorine in control zooxanthellae unexposed to host extract approximately doubled during $14 \mathrm{~d}$ of exposure to PAR + UVR, whereas it did not change in zooxanthellae exposed to host extract (ANOVA, p > 0.05). By Day 14, zooxanthellae exposed to host extract contained less shinorine than did unexposed controls (SNK, $\mathrm{p}=0.001)$. Traces of mycosporine-glycine were not quantifiable. No other MAAs were detected in the zooxanthellae. HPLC analysis of the culture media showed that no novel MAAs had been released by the zooxanthellae, and that the amounts of MAAs that were present in the media were from 46 to $86 \%$ of the total amount of MAAs added via the host extract derived from UVexposed corals. We do not know whether the missing balance (14 to $54 \%$ ) of the exogenous MAAs added to the media in the host extract were metabolized by zooxanthellae or bacteria, or photochemically de- 

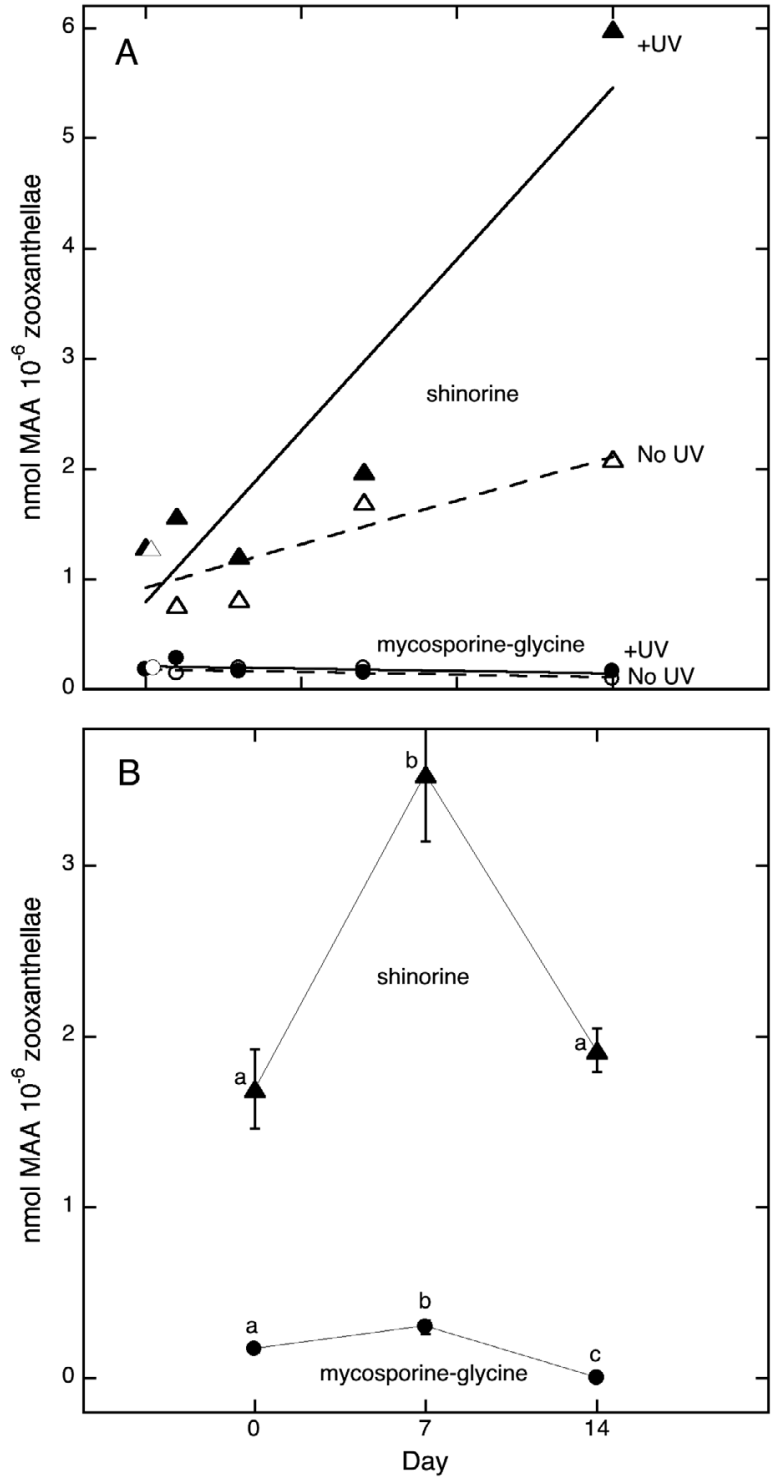

Fig. 8. Cultured zooxanthellae isolated from Stylophora pistillata. (A) Concentrations of shinorine $(\boldsymbol{\Lambda}, \Delta)$ and mycosporineglycine $(\bullet, 0)$ in cultures exposed to PAR + UVR (solid symbols, solid line) or to PAR only (open symbols, broken line). Only shinorine responded to the presence of UVR $\left(r^{2}=0.878\right.$, $\mathrm{n}=5, \mathrm{p}=0.0187$ ), and MAA concentrations in cultures not exposed to UVR did not change significantly with time $(p>$ 0.05). (B) Concentrations of shinorine ( $\mathbf{\Delta})$ and mycosporineglycine (๑) in cultures exposed to PAR + UVR for 7 and $14 \mathrm{~d}$ in a second experiment. For each MAA, treatment means that are significantly different (SNK tests, $\mathrm{p}<0.05$ ) have different lower-case letters $(a, b, c)$. Data are mean $\pm S E, n=3$. If no error bars are visible, they are smaller than the size of the symbol

graded in the chemically complex culture medium, during the $2 \mathrm{wk}$ of the experiment. The results do indicate that any 'host factor' in the host extract does not qualitatively change the complement of MAAs made by $S$. pistillata zooxanthellae in culture, nor apparently

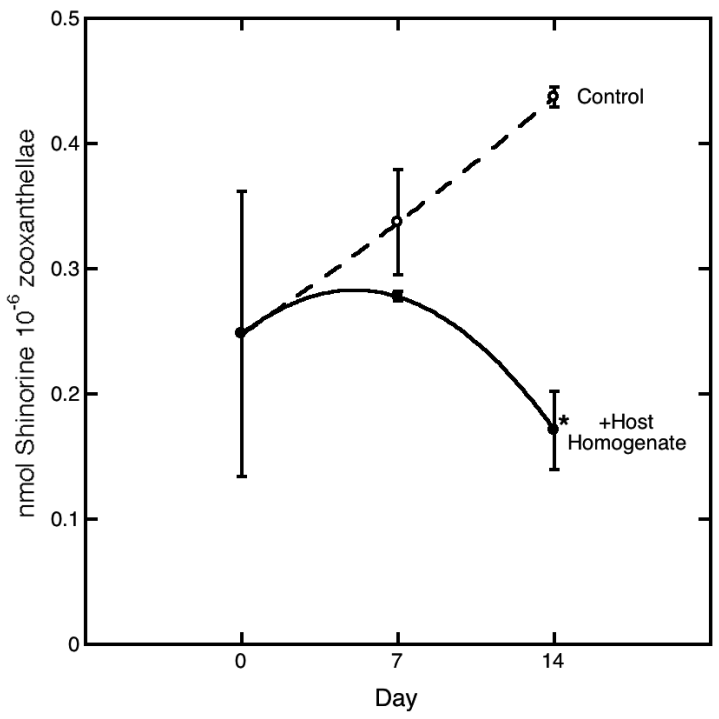

Fig. 9. Cultured zooxanthellae isolated from Stylophora pistillata. Concentration of shinorine in control cultures grown under PAR + UVR without the addition of host extract (open symbols, broken line), and in cultures to which host extract was added on Days 0 and 7 (solid symbols, solid line). Data are mean $\pm \mathrm{SE}, \mathrm{n}=3$. ANOVA indicated a significant effect of treatment $\left(F_{1,8}=36.968, \mathrm{p}=0.0003\right)$, no effect of time (day; $\left.F_{1,8}=0.022, \mathrm{p}=0.885\right)$, and a significant interaction between treatment and time $\left(F_{1,8}=14.787, \mathrm{p}=0.0049\right)$. Asterisk $(*)$ denotes significant difference between control cultures and those receiving host extract $(\mathrm{SNK}, \mathrm{p}<0.05)$

does it elicit a wholesale export of MAAs from the zooxanthellae to the medium, although the extract does seem to diminish their biosynthesis of shinorine.

Methanolic extracts of freshly isolated zooxanthellae (FIZ) show only traces of MAAs in their absorption spectra, whereas extracts of other pieces of the colony from which the zooxanthellae were isolated evince high concentrations of MAAs (Fig. 10). Thus, virtually all of the MAAs in Stylophora pistillata exposed to PAR + UVR are located in the host tissue.

\section{DISCUSSION}

\section{Effect of feeding on accumulation of MAAs}

Nubbins of Stylophora pistillata that were given Artemia sp. nauplii did not accumulate significantly higher concentrations of MAAs per $\mathrm{cm}^{2}$ of colony surface area than did starved colonies (Fig. 1C). This unchanging concentration of MAAs per $\mathrm{cm}^{2}$, despite the $56 \%$ decline in protein level during the final $2 \mathrm{wk}$, suggests that MAAs are preferentially conserved during reabsorption of tissue (Franzisket 1970) and catabolism of protein in starving corals. Considering the 


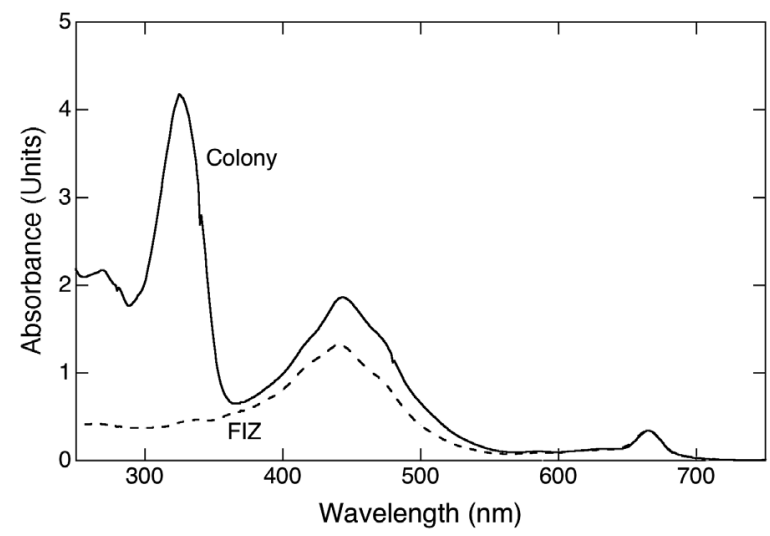

Fig. 10. Stylophora pistillata. Absorption spectra of methanolic extracts of a piece of a colony exposed to PAR + UVR for $28 \mathrm{~d}$ and of freshly isolated zooxanthellae (FIZ) from another piece of the same colony. Spectra are normalized to the chlorophyll peak at $665 \mathrm{~nm}$. Traces of MAAs present in the FIZ were not quantifiable

substantial cost of synthesizing MAAs de novo (perhaps 60 ATP-equivalents or 300 mol photons per mol MAA: Haslam 1993, Raven 1991, Shick \& Dunlap 2002), their UV-protective role may select for their preferential retention. Once accumulated, MAAs have residence times of weeks to months in tissues (Gleason 1993, Adams \& Shick 1996, 2001, Carroll \& Shick 1996, Newman et al. 2000) and are photochemically stable (Adams \& Shick 1996, Conde et al. 2000, Shick et al. 2000), which in organisms that produce MAAs would save the metabolic cost of ongoing biosynthesis to offset a high rate of loss or degradation.

Starvation of Stylophora pistillata also leads to a lower density of zooxanthellae in its tissues (Titlyanov et al. 2001, Ferrier-Pagès et al. 2003, Houlbrèque et al. 2003), and it is the zooxanthellae that synthesize the MAAs (Dunlap \& Shick 1998, Banaszak et al. 2000, Karentz 2001, Shick \& Dunlap 2002; but see Shick et al. 2002). Starved colonies lagged behind fed colonies in the initial accumulation of MAAs (Fig. 1C), which was pronounced at Day 7, when the concentration of chlorophyll a was significantly lower in the starved colonies (Fig. 1D). The loss of chlorophyll a from starved corals between Days 7 and 14 (60\% decline) was greater than the loss of colony protein $(6 \%$ decline). Therefore, the continued increase in MAAs per $\mathrm{cm}^{2}$ of colony surface may indicate an increase in the rate of UV-induced production of MAAs per unit chlorophyll $a$, perhaps as a compensation (afforded by decreased self-shading) for declining numbers of zooxanthellae and despite ongoing starvation (with ammonium derived from protein catabolism being recycled by the zooxanthellae: Rahav et al. 1989). This would indicate a priority for producing UV defenses during acute exposure to UVR despite nutritional stress, although this may differ among colonies (see below).

That fed corals did not accumulate higher concentrations of MAAs than did starved colonies also indicates that dietary MAAs are of little quantitative importance in this phototrophic symbiosis. This is relevant for analyzing and interpreting experiments on the biosynthesis and conversion of MAAs. The quantitative contribution of dietary MAAs (and of gadusols, precursors to MAAs) can be calculated. The Artemia sp. nauplii used in these experiments contained $0.08 \mathrm{nmol}$ of mycosporine-2 glycine $\mathrm{g}^{-1}$ wet weight. Gadusols could not be measured, but can be estimated from the data of Grant et al. (1985), who found that gadusols were from 4.5 to 16.2 times more concentrated than MAAs in diverse Artemia cysts and nauplii. Thus, the maximum estimated amount of gadusols present in the nauplii used in our experiment was $0.08 \times 16.2=$ $1.296 \mathrm{nmol} \mathrm{g}^{-1}$. Each feeding provided $10 \mathrm{~g}$ of nauplii, and there were 2 such feedings each week. The experiment began with 21 feeding nubbins (including controls) in the aquarium, with 3 or 6 nubbins being removed for analysis on Days 3, 7, and 14 .

Combining the amount of mycosporine-2 glycine and gadusols available per nubbin at each feeding (mycosporine-2 glycine: range 0.04 to $0.14 \mathrm{nmol}$; gadusols: 0.62 to $2.16 \mathrm{nmol}$ ) gives the total MAA and gadusols available per nubbin during the $28 \mathrm{~d}$ of the experiment, which were $0.78 \mathrm{nmol}$ mycosporine-2 glycine and 12.14 nmol gadusols. By Day 28, each remaining nubbin averaged $9.3 \mathrm{mg}$ total protein and had $31.77 \mathrm{nmol}$ total MAAs $\mathrm{mg}^{-1}$ protein, or $295.46 \mathrm{nmol}$ MAA per nubbin. Therefore, the cumulative amount of mycosporine-2 glycine + gadusol available per nubbin (12.92 nmol) divided by the MAA content of a nubbin (295.46 nmol) shows that only $4.4 \%$ of the MAAs in the corals at the end of the experiment could have come from the diet. Even this is an overestimate, because it assumes that corals would have captured all of the nauplii in the aquarium (which was not the case because of the removal of some nauplii in the water flow through the aquarium), and that corals would have been $100 \%$ efficient in retaining the dietary compounds. MichalekWagner (2001) likewise concludes that the stable complement of MAAs in small-polyped soft corals in the field is derived preponderantly from endogenous biosynthesis, rather than from variable dietary sources.

A similar calculation shows that in the fed corals unexposed to UVR, all of the $6.231 \mathrm{nmol}$ of total MAAs that they accumulated could be accounted for by dietary mycosporine-2 glycine and gadusols. By Day 28, the only secondary MAA to appear in these colonies was palythine, at one-half the concentration of mycosporine-2 glycine (data not shown), from which it might have been produced (Shick 2004, and below). 


\section{Effects of ammonium enrichment on accumulation of MAAs}

If the MAAs in Stylophora pistillata are preponderantly endogenous, then their accumulation during starvation of the coral must originate in the fixation of carbon and assimilation of nitrogen by the zooxanthellae. Our experiments reveal a complex relationship in the response of $S$. pistillata to ammonium enrichment, including differential effects on the levels of chlorophyll $a$, and primary and secondary MAAs, in 2 different colonies (Table 1).

There was no clear overall effect of ammoniumenrichment $(10 \mu \mathrm{M})$ on the accumulation of MAAs, but this was because of a significant difference between the 2 colonies, and an interaction between colony and treatment, in the corals' response to ammonium (Table 1). This in turn seems related to the different effects of ammonium on the level of chlorophyll $a$ in the 2 colonies. In ammonium-enriched nubbins of both colonies, the final concentration of MAAs was the same (Fig. 2A,C), as was the final concentration of chlorophyll a (Fig. 2B,D). In control colonies, however, the final concentration of MAAs was about $45 \%$ lower in Colony SP1 than SP2 (Fig. 2A,C), whereas the final concentration of chlorophyll a in SP1 was double that in SP2 (Fig. 2B,D). Thus, under N-limited conditions, the zooxanthellae used the available nitrogen to make either MAAs or chlorophyll, and the 2 colonies reacted differently. Although Colony SP2 achieved greater biosynthesis of MAAs than did SP1 under N-limiting conditions, this came at the expense of a drastic decline in its chlorophyll a concentration (but not its zooxanthella density: Fig. 2B,D), with unmeasured effects on colony primary production.

Another difference between Colonies SP1 and SP2 was the effect of ammonium-enrichment on the accumulation of primary, Symbiodinium-MAAs (mycosporine-glycine, shinorine, porphyra-334, and mycosporine-2 glycine). In SP1, adding ammonium caused the colonies to enhance their biosynthesis of primary MAAs, with no consistent effect on the major secondary MAAs, and overall a higher concentration of total MAAs resulted from ammonium-enrichment. The opposite is true for Colony SP2, where control nubbins had higher concentrations of total MAAs at the end of the experiment, largely because of their higher levels of primary MAAs, there being no effect of ammoniumenrichment on secondary MAAs.

It is perhaps not surprising that supplementing corals with ammonium has a larger effect on primary than on secondary MAAs, for it is primary MAAs that are synthesized de novo in the zooxanthellae (where most of the exogenous ammonium is assimilated: Rahav et al. 1989, Grover et al. 2002), and then secon- darily modified in the host or its associated bacteria (Dunlap \& Shick 1998, Shick \& Dunlap 2002, Shick 2004). In particular, it is the primary MAAs shinorine, porphyra-334, and mycosporine-2 glycine whose biosynthesis requires the addition of an amino acid (serine, threonine, and glycine, respectively) to the progenitor MAA, mycosporine-gycine. Forming most of the secondary MAAs involves rearrangements of existing amino acid substituents, plus methylation (see Shick 2004), but conserves nitrogen when glycine is removed at $\mathrm{C} 3$-i.e. forming secondary MAAs does not generally require additional nitrogen.

SP1 accumulated greater amounts of secondary MAAs compared with SP2 (Fig. 5). Because the accumulation of these MAAs was not affected by ammonium enrichment, their biosynthesis presumably depends on the activities of the putative enzymes that convert primary to secondary MAAs, and on the enzymes' substrate concentration (i.e. primary MAAs: Portwich \& Garcia-Pichel 2003, Shick 2004). A hint of the latter relationship may be seen in Fig. 5, where the higher rate of accumulation of secondary MAAs from Days 15 to 30 is associated with the higher concentration of primary MAAs on Day 15 (which differs between the colonies). Presumably some entity (zooxanthellae, host, or bacteria) in Colony SP1 has greater titres or specific activities of the putative enzymes involved in converting primary to secondary MAAs, but testing this awaits identification of the enzymes.

A final, major difference between the experimental colonies is the absence of 3 MAAs (most notably the principal primary MAA, mycosporine-2 glycine, and the major secondary MAA, palythine) from SP2 that are present in SP1 (cf. Figs. $3 \& 4$ ). The absence of mycosporine-2 glycine may reflect a genotypic difference between the zooxanthellae present in SP2 and those in SP1. The clone of Symbiodinium investigated by Banaszak et al. (2000), which lacks mycosporine-2 glycine, is of ITS 2 (Internal Transcribed Spacer 2) Type A1, as are the endosymbionts in both colonies SP1 and SP2, although this does not preclude other genotypic differences among these groups (LaJeunesse 2001, and pers. comm.). Therefore, at least 2 groups of Symbiodinium within ITS Type A1 have representatives that do not synthesize mycosporine-2 glycine, and the presence of this MAA in Colony SP1 that also harbors Type A1 algae may indicate a specific difference in its endosymbionts that is not resolved by ITS 2 typing. Had we used only 1 colony of Stylophora pistillata, or only the extant culture of zooxanthellae from this coral, this metabolic diversity would not have been apparent.

The absence of both mycosporine-2 glycine and palythine-the 2 most concentrated MAAs in SP1 (Fig. 3) - from SP2, in addition to the complementary changes 
in these 2 MAAs as steady-state concentrations of total MAAs are approached (Fig. 3), strongly supports a biosynthetic relationship between these compounds in Stylophora pistillata, as proposed by Shick (2004). In that paper, based on their complementary kinetics and stoichiometric balance, a precursor (mycosporine-2 glycine)-product (palythine) relationship was proposed, rather than a production of palythine from mycosporine-glycine by its reductive amination, as is sometimes suggested. This does not preclude other routes of the biosynthesis of palythine, e.g. via mycosporine-glycine (Whitehead et al. 2001) or shinorine (Franklin et al. 1999) in other organisms, depending on their complements of the enzymes necessary for the conversions.

How much of the ammonium taken up by starved colonies is used in the biosynthesis of MAAs? To answer this, we consider Days 0 to 15 and Days 15 to 30 separately. This is because colony protein remained fairly stable during the early stages of starvation but declined later (Fig. 2A,C), when nitrogen balance included the net degradation of endogenous proteins. In control nubbins of Colony SP1 exposed only to ambient $(<0.4 \mu \mathrm{M}) \mathrm{NH}_{4}{ }^{+}$, accumulation of MAAs would consume $20 \%$ of the cumulative ammonium-N absorbed during the first $15 \mathrm{~d}$ (based on the rates of ammonium uptake measured for starved corals by Grover et al. 2002); a similar value ( $24 \%$ ) holds for control nubbins of SP2 (Table 2). Under ammonium enrichment, when ammonium uptake rates are 25-fold higher, the use of ammonium-N in MAAs would fall to less than $1 \%$.

Therefore, at an ambient ammonium concentration $<0.4 \mu \mathrm{M}$, similar to those in reef waters (Falkowski et al. 1993, Hoegh-Guldberg \& Williamson 1999), the uptake of ammonium is sufficient to allow the observed production of MAAs, although these would account for a large fraction $(\geq 20 \%)$ of the ammonium$\mathrm{N}$ that is also needed to maintain other functions in the zooxanthellae. In colony SP2, this large allocation to MAAs is correlated with a decline in chlorophyll $a$, which may indicate that initially the prioritization of MAA biosynthesis for UV-protection is at the expense of the size of the algal photosystem. Elevating the external ammonium concentration 25-fold results in little or no further change in MAA concentration (Fig. 2A,C) during the next $15 \mathrm{~d}$ but it sustains the level of chlorophyll a (Fig. 2B,D), which by comparison indicates the priority that is placed on MAAs when nitrogen is limiting to the zooxanthellae. To put these data in perspective, on Day 15 the average concentration of MAAs is about 12 times that of chlorophyll a ( 60 nmol MAAs cm ${ }^{-2} ; \sim 5 \mathrm{nmol} \mathrm{chl} \mathrm{a} \mathrm{cm}^{-2}$ ).

Between Days 15 and 30, when the effects of ammonium-enrichment are differentially manifested in the 2 colonies, the rate of MAA accumulation declines, with a corresponding decline in the fraction of ammonium$\mathrm{N}$ allocated to these compounds (Table 2). Here, ammonium enrichment significantly increases the accumulation of MAAs in Colony SP1, while Colony SP2 now allocates more amonium-N to chlorophyll $a$. The calculation is perhaps less meaningful here because colony protein has also decreased substantially (Fig. 2A,C), and the fate of enhanced ammonia produced endogenously from protein catabolism in atrophying coral tissues is uncertain.

\section{Effect of UVR alone, and of DCMU, on accumulation of MAAs}

It is UV-B (280 to $320 \mathrm{~nm}$ ) in particular that stimulates the accumulation of MAAs in Stylophora pistillata (Shick et al. 1999) and in cultured Clade A zooxanthellae isolated from Porites porites (J. E. Rogers, Gulf Ecology Division, U.S. Environmental Protection Agency pers. comm.). UVR is a stimulus that induces the production of MAAs but is not itself required to drive any photoenzymes involved in this biosynthesis (Portwich \& Garcia-Pichel 2003, Shick 2004). Prolonged exposure to UVR may nevertheless be needed to sustain the levels of enzymes involved in the production of primary MAAs, which may have short halflives and rapid turnover (Shick 2004). Whether exposure to UVR alone in the absence of PAR can support the accumulation of MAAs in corals has not been tested heretofore.

Our results using Schott UG11 filters that transmit only UVR (and some PAR > $650 \mathrm{~nm}$ ) indicate that UVR alone does not support large-scale biosynthesis of MAAs in Stylophora pistillata (Table 2), which showed substantial increases only in mycosporine-2 glycine and palythine, with barely quantifiable increases in 2 secondary MAAs (mycosporine-NMA:serine and mycosporineNMA:threonine). Colonies exposed to PAR + UVR showed significant further increases in mycosporine-2 glycine and palythine, as well as in all primary MAAs but not secondary MAAs (other than palythine). The predominant stimulation by UVR alone of palythine as well as mycosporine-2 glycine makes sense in light of the apparent metabolic linkage between these MAAs, although the bioenergetics and carbon source of these MAAs under such conditions are uncertain.

The lack of production of the other primary MAAs (apart from traces of mycosporine-glycine) under UVR alone suggests that mycosporine-2 glycine was synthesized from precursors (e.g. dietary deoxgadusol) already present in the corals and not via photosynthesis, i.e. the zooxanthellae may have been functioning heterotrophically (Steen 1986) and produced MAAs when stimulated to do so by UVR. Although the UG11 filter 
transmitted a small amount of PAR $>650 \mathrm{~nm}(0.6 \mu \mathrm{mol}$ quanta $\mathrm{m}^{-2} \mathrm{~s}^{-1}$, which was only $0.29 \%$ of the fullspectrum irradiance of PAR incident on the corals exposed to PAR + UVR), this is well below the compensation irradiance in these colonies of Stylophora pistillata (Romaine-Lioud et al. 1997); such a low level of PAR likely could not support production of mycosporine-2 glycine and palythine at levels of 26 and $41 \%$, respectively, of that seen under full PAR + UVR. Alternatively, the combined irradiance of UVR plus red light passing the UG11 filter was $\sim 11 \%$ of the total irradiance falling on colonies receiving full PAR + UVR, so if the zooxanthellae in hospite could efficiently use UV wavelengths in photosynthesis (Halldal 1968), this might support the observed rates of MAA biosynthesis, particularly if MAAs were prioritized under enhanced UVR.

Further insights are forthcoming from the experiment in which corals were exposed to PAR + UVR for $14 \mathrm{~d}$, and then exposed for a further $7 \mathrm{~d}$ to PAR + UVR, PAR only, or UVR only. This experiment was undertaken to investigate the wavelength-dependence of the maintenance of primary MAAs and their conversion to secondary MAAs, and particularly whether UVR alone had an effect. There was no net increase in total MAAs after Day 14 (the start of the experiment) under any condition (Fig. 6), consistent with earlier results (Shick 2004).

None of the secondary MAAs (except palythineserine sulfate) showed a significant change under any condition, which was unlike the 2004 results, where secondary MAAs increased between Days 14 and 28 under PAR + UVR. Perhaps only 7 additional days (rather than $14 \mathrm{~d}$, as earlier) were not enough to produce a significant further increase, particularly because the corals were in beakers, not in the flow-through experimental aquarium. This idea is supported by the tendency of all secondary MAAs in the present experiment to increase, albeit not significantly; such an increase would be expected from the significant decrease in primary MAAs and no net change in total MAAs.

The most concentrated primary MAA, mycosporine- 2 glycine, remained at the same level as at the start of the experiment if maintained under PAR + UVR $;$ like the primary MAAs shinorine and porphyra-334, its concentration decreased under only PAR (consistent with the earlier results) or only UVR. Therefore, mycosporine-2 glycine requires both PAR and UVR for its ongoing biosynthesis. This implies that PAR is required for the photosynthetic carbon fixation to support the biosynthesis of this primary MAA, and that the biosynthetic pathway is modulated by UVR (perhaps by continually inducing the necessary enzyme[s]: Shick 2004, and above). UVR alone is not sufficient to support the largescale production of mycosporine- 2 glycine that occurs when PAR is also present (Figs. 3 \& 6), but it may support low levels of such biosynthesis (Table 3). In comparison, how Chondrus crispus can increase MAAs 90-fold during $7 \mathrm{~d}$ under the UG11 filter (i.e., under UVR and minimal PAR) (Karsten et al. 1998) is unknown, but the cyanobacterium Chlorogloeopsis sp. produces MAAs heterotrophically when grown in sucrose medium and stimulated by UV-B (Portwich \& Garcia-Pichel 2000).

In Stylophora pistillata, the concentration of mycosporine-glycine (from which all other MAAs are presumably derived) was sustained beyond the start of the experiment on Day 14 in the presence of PAR + UVR but not under PAR alone (again consistent with results in Shick 2004), and not if only UVR was present. Therefore, the accumulation of mycosporine-glycine requires both photosynthesis as a carbon source and UV-modulation of the biosynthetic pathway. This is new information, which was not found in our earlier experiment (Shick 2004), where this MAA disappeared by Day 28 under all conditions.

Palythine-serine sulfate, the only secondary MAA to increase signficantly after the start of the experiment, did so under PAR + UVR and PAR alone, and perhaps under UVR alone. This suggests that its accumulation requires the photosynthetic production of some precursor (which remains unidentified and, oddly, seems not to be palythine-serine: Shick 2004), and that UVR might modulate the conversion of an extant primary MAA or other precursor to palythine-serine sulfate.

Our attempts to use DCMU to block photosynthesis under full PAR + UVR irradiance and assess the effect on MAA accumulation also had equivocal results. Nubbins exposed to $10^{-5} \mathrm{M}$ DCMU (which in shortterm experiments lasting hours would have reduced photosynthetic carbon fixation by about $83 \%$ : Vandermeulen et al. 1972) for $5 \mathrm{~d}$ accumulated a concentration of MAAs $62 \%$ lower than in controls unexposed to DCMU. Most of the latter decrease was owing to significant reductions in the accumulation of 3 of the 4 primary MAAs (but not porphyra-334) thought to be produced by the zooxanthellae. Therefore, our results collectively demonstrate that photosynthesis is required for the biosynthesis of MAAs in Stylophora pistillata, as shown for free-living dinoflagellates by Carreto et al. (1990), but the extent to which some net accumulation of MAAs might be independent of photosynthesis could not be assessed definitively.

\section{Experiments with cultured zooxanthellae from Stylophora pistillata}

Prior to the start of exposure to UVR, our culture of zooxanthellae isolated from Stylophora pistillata by Banaszak et al. (2000) contained about the same con- 
centration of shinorine (Fig. 8) as reported by those authors $\left(\sim 1.2 \mathrm{nmol} 10^{-6}\right.$ cells) for cultures harvested after $30 \mathrm{~d}$ of exposure to PAR + UVR. In our experiments, shinorine increased either linearly (Fig. 8A) or transiently (Fig. 8B) during exposure to PAR + UVR, in the latter case returning to the level reported by Banaszak et al. (2000) for UV-exposed cultures. The basis for the different response in our 2 experiments is unknown, and although zooxanthella cultures may differ quantitatively in their MAA content with age (Banaszak \& Trench 1995), in the present cases the experimental cultures were all begun fresh from stock cultures at Day 0.

Unlike Banaszak et al. (2000) who did not find it, we measured low levels of mycosporine-glycine in the cultures of zooxanthellae from Stylophora pistillata (Fig. 8A,B). This might be because we extracted fresh cells at room temperature in $80 \%$ aqueous methanol with sonic disruption, whereas they extracted lyophilized zooxanthellae in cold $100 \%$ methanol, a protocol that may not be optimal for solubilizing MAAs from microalgae (Tartarotti \& Sommaruga 2002), particularly if they have been lyophilized, in which case at least partial rehydration is required (J. M. Shick unpubl.). Banaszak et al. (2000) did, however, find mycosporineglycine in cultures of zooxanthellae isolated from other symbioses, probably because their MAA concentrations were higher than in the culture from S. pistillata. In principle, mycosporine-glycine should be present in all organisms that produce MAAs because it is the progenitor MAA from which the others are synthesized (Shick \& Dunlap 2002, Portwich \& Garcia-Pichel 2003). In our experiments, the concentration of mycosporine-glycine responded scarcely (Fig. 8B) or not at all (Fig. 8A) to UVR, but this might be because it is kept low by its conversion to shinorine (also see Shick 2004).

Throughout this manuscript, and following Shick (2004), we have referred to mycosporine-glycine, shinorine, porphyra-334, and mycosporine-2 glycine as primary or Symbiodinium-MAAs because they are the only ones synthesized collectively by diverse cultures of Symbiodinium in ITS group A (Banaszak et al. 2000, J. M. Shick \& C. Ferrier-Pagès unpubl.). In our experiments on Stylophora pistillata we assume that these 4 MAAs might be synthesized by the zooxanthellae in hospite, even though the one clonal culture of algae isolated from a colony of this coral species produces only mycosporine-glycine and shinorine. We have not been able to culture zooxanthellae from our experimental colonies, so it is possible that the zooxanthellae that are present can synthesize the additional 2 MAAs known from other dinoflagellates in Clade A. Also, as noted by Banaszak et al. (2000), zooxanthellae in hospite might synthesize MAAs that they do not in culture, if they receive some necessary stimulus or substrate from the host. Freshly isolated zooxanthellae (FIZ) from our MAA-replete experimental colonies of $S$. pistillata contain only traces of unidentifiable MAAs (Fig. 10), so this does not answer the question of what MAAs they produce in hospite. Moreover, any 'host factor' that might have been present in the host extract that we added to the cultures did not stimulate qualitative changes in the alga's complement of MAAs. (It might be that the concentration of any such host factor was too low to elicit the synthesis of additional MAAs, particularly because host factor in hospite would be concentrated within the symbiosome. However, in a preliminary experiment in which the CZ were exposed to a 10 -fold higher concentration of extract, they died within 2 d.)

Compared with control CZ, those that were exposed to host extract eventually showed a decrease in shinorine concentration (Fig. 9), which was not accompanied by a release of shinorine to the culture medium. Apparently the host extract inhibited the biosynthesis of MAAs in the CZ, so it remains to be seen whether zooxanthellae in hospite produce MAAs other than what they do in culture, and at what rate. Shick et al. (1995) found that FIZ from field-fresh Acropora microphthalma, like the intact colony, contain mycosporine-glycine, palythine, asterina-330, and palythinol (plus smaller amounts of then-unidentified MAAs, whose chromatographic properties now suggest that they include shinorine, porphyra-334, and mycosporine-2 glycine). Whether several of the foregoing MAAs that are not reported from CZ (Banaszak et al. 2000, and present study) are induced by some stimulus from the host, or perhaps are translocated from the host to the zooxanthellae, is unknown. Also, MAAs are present in FIZ from several genera of Caribbean corals hosting clades of zooxanthellae that do not produce MAAs in culture (J. M. Shick et al. unpubl.), but whether this indicates the presence in the corals of additional zooxanthellae that do not appear in cultures, or of metabolic differences of the same zooxanthellae in hospite and in vitro is unknown. The latter follows from many previous observations summarized by Stochaj \& Grossman (1997), who documented differential protein expression between $\mathrm{CZ}$ and those in hospite. The partitioning of the biosynthesis, conversion, and translocation of MAAs between the symbiotic partners is far from being understood.

Is the rate of biosynthesis of MAAs by $\mathrm{CZ}$ high enough to account for the accumulation of MAAs in the coral, if zooxanthellae in hospite produce MAAs at the same rate as do the algae in vitro? In the kinetic experiment (Fig. 8A), where shinorine increased linearly after acute exposure of $\mathrm{CZ}$ to UVR, its daily rate of accumulation was $0.313 \mathrm{nmol} \mathrm{d}^{-1} 10^{-6}$ zooxanthellae (the concentration of mycosporine-glycine did not 
change). We can compare this with the accumulation of total MAAs in the control corals used in the ammonium-enrichment experiment (which were starved to avoid dietary input of MAAs), and for which we have counts of zooxanthella numbers. The calculations assume that all of the MAAs in the corals were derived from shinorine-equivalents.

In control corals exposed to PAR + UVR and ambient ammonium, the average density of zooxanthellae in Colonies SP1 and SP2 between Days 0 and 15 was $2.3 \times 10^{6}$ zooxanthellae $\mathrm{cm}^{-2}$. Thus, the maximum potential biosynthesis of MAAs in the coral by this density of zooxanthellae in $15 \mathrm{~d}$ is $\left(0.313 \mathrm{nmol} \mathrm{d}^{-1} 10^{-6}\right.$ zooxanthellae $) \times\left(2.3 \times 10^{6}\right.$ zooxanthellae $\left.\mathrm{cm}^{-2}\right) \times 15 \mathrm{~d}$ $=10.8 \mathrm{nmol} \mathrm{MAA} \mathrm{cm}^{-2}$. In the control corals, the actual accumulation of total MAAs (average for colonies SP1 and SP2) from Days 0 to 15 was $62.3 \mathrm{nmol} \mathrm{cm}{ }^{-2}$ (Fig. 2A,C), so that the maximum measured rate of MAA (shinorine) biosynthesis in the CZ could account only for $17.3 \%(10.8 / 62.3)$ of the MAAs accumulated by the corals. The lower rates of shinorine biosynthesis in the 'host factor' experiment (Fig. 9) would support far less than the measured accumulation of MAAs in the corals.

The balance may, however, be closer than the calculated $17.3 \%$, if the zooxanthellae in hospite produce all 4 Symbiodinium-MAAs and not only shinorine (and traces of mycosporine-glycine), with the caveats discussed above regarding qualitative differences in the MAA complements of zooxanthellae among genotypes and in hospite versus in vitro. If all 4 primary MAAs are produced at the same maximal rate as shinorine, the balance in Colony SP1 would be $80 \%$ (i.e. [10.5 nmol MAA cm ${ }^{-2} \times 4$ MAAs]/52.5 nmol MAA cm$~^{-2}$ ). Zooxanthellae in Colony SP2 do not produce mycosporine-2 glycine, so if they synthesize the 2 other primary MAAs at the same rate as shinorine, the balance is $45 \%$ $([10.8 \times 3] / 72.1)$.

Thus, if we use the maximal observed rate of MAA biosynthesis by CZ from Stylophora pistillata, this surely lies within an order of magnitude (17.5 to $80 \%$ ) of the observed rate of MAA accumulation in the coral colony. Given the many foregoing uncertainties, our experiments with CZ support the conclusion in the feeding experiment: zooxanthellae are the primary source of MAAs for colonies of S. pistillata.

\section{CONCLUSIONS AND PROSPECTS}

In Stylophora pistillata, the MAAs that accumulate during acute exposure to UVR are produced endogenously, there being little input of dietary MAAs in this small-polyped, zooxanthellate coral. When the coral is starved, it continues to accumulate MAAs and to con- serve them disproportionally compared with declining protein and chlorophyll $a$, which indicates the priority placed on the maintenance of this defense against UVR. The endogenous production of MAAs reflects the fixation of $\mathrm{CO}_{2}$ and assimilation of inorganic nitrogen by the zooxanthellae, and when the latter nutrient is limiting, zooxanthellae in hospite use it to make either MAAs or chlorophyll, with inter-colony differences in the partitioning between these uses. Enriching the seawater with ammonium has relatively little effect on the rate of accumulating MAAs, which again suggests that the zooxanthellae are poised to maximize rates of MAA-biosynthesis even under oligotrophic conditions. The rate of biosynthesis of MAAs by zooxanthellae in culture is nearly enough to support the rate of MAA-accumulation in the coral. This biosynthesis requires photosynthesis, perhaps initially including the utilization of UV wavelengths by the zooxanthellae in hospite.

In Stylophora pistillata, the qualitative discordance between the MAA complement in the coral and the MAAs that are collectively produced by 14 isolates of zooxanthellae in Clade A (including 1 type isolated from S. pistillata) suggests that the 4 primary Symbiodinium-MAAs are modified by the host (and perhaps associated bacteria) to form an additional 6 secondary MAAs that characterize the coral colony.

The conclusion that the host produces secondary MAAs from primary MAAs translocated from the algae is not definitive, because the ideal experimental symbiosis has not been found. Many zooxanthellate corals do not yield culturable algae, and the work reported in Shick et al. (1999), Shick (2004), and in this paper compared MAAs in experimental colonies of Stylophora pistillata from the Red Sea with those in CZ isolated from a different colony of this coral from the same area (Banaszak et al. 2000), although all of the zooxanthellae are of the same ITS type, A1 (LaJeunesse 2001 and T. C. LaJeunesse pers. comm.). If the zooxanthellae in hospite are not stimulated by the host to alter qualitatively the MAAs that they produce, the inference is that the MAAs present in the coral beyond the 4 known from cultured Symbiodinium spp. are produced by the host. FIZ from $S$. pistillata contain only traces of unidentified MAAs, so the complement of MAAs in its FIZ cannot be compared with that in the intact symbiosis or the cultures.

The ideal experiment, in which MAAs could be compared among the symbiotic coral, the FIZ from the same colony, and all zooxanthellae identified and cultured from that colony, has not been performed. The experiment is needed because zooxanthellae of different genotypes, even in the same clade, may produce different MAAs, and because a coral may harbor algae of several genotypes, not all of which are culturable 
(Santos et al. 2001). Our results with Colonies SP1 and SP2 (i.e. the presence of mycosporine-2 glycine in the former but not the latter) moreover indicate that the complement of primary MAAs may be a useful taxonomic character to distinguish among zooxanthellae that are not currently separable by molecular genetic techniques.

Most recent research has linked episodes of widespread coral bleaching to abnormally high temperatures and the interacting effects of PAR (Hoegh-Guldberg 1999), and attention is turning toward genotypespecific thermal tolerances and photosynthetic performance in diverse zooxanthellae as determinants of bleaching resistance and recovery (Baker 2003, 2004, Edmunds \& Gates 2003, Knowlton \& Rohwer 2003). Surprisingly, the contributing effects of UVR have not figured in recent mechanistic experiments (even those conducted in full sunlight) on coral bleaching and dysfunction (Jones et al. 1998, Warner et al. 1999, Yakoleva \& Hidaka 2004, but see Lesser \& Farrell 2004). As more sensitive indicators of UV-induced damage are applied to corals, and as subtler determinants of the submarine UV environment are elucidated (Anderson et al. 2001), studies of the involvement of UVR in coral bleaching and well-being may increase, including potential protective mechanisms of MAAs.

LaJeunesse (2002) in particular noted the restriction of Clade A zooxanthellae to hosts living in shallow water, where fluences of UVR are high (as, necessarily, is PAR: Jokiel et al. 1997, Jokiel 2004), and associated this with the apparently unique ability (among Symbiodinium spp.) of members of this clade to synthesize MAAs. It remains to be seen whether genotypically diverse zooxanthellae within Clade A predominate in different UV environments and whether this is linked specifically to their UV sensitivity, and in turn to differences in their capacity to synthesize sunscreens. Such differences might involve variations in the uptake of inorganic nitrogen by the host, assimilation of the nitrogen by the zooxanthellae, partitioning of the nitrogen between the partners, and the involvement of genotypic variation in both partners in these functions, as well as the thermal sensitivity of the several processes.

Acknowledgements. J.M.S. thanks his co-authors for their hospitality and collegiality during his visits to the Centre Scientifique de Monaco (CSM), which supported these visits, as, earlier, did the Observatoire Océanologique Européen of the CSM under the directorship of J. Jaubert. P. Payan and D. Allemand (University of Nice-Sophia Antipolis) generously provided to J.M.S. a visiting professorship in the Laboratoire de Physiologie et Toxicologie Environnementales. We appreciate the technical and other help provided at CSM by C. Richard, C. Emery, S. Reynaud, E. Tambutté, J. Chisholm, and M. Marchioretti. H. Claustre (Laboratoire d'Océanographie de Villefranche) kindly lent his HPLC, and J. Ras assisted in optimizing it. P. Alvarez of the Musée Océanographique de Monaco expertly fabricated the optical filter holders, components of the experimental aquarium, and other apparatus. T. LaJeunesse (University of Georgia) identified the clade of zooxanthellae resident in our experimental colonies of Stylophora pistillata and provided the zooxanthella culture, as well as insightful discussions. W. Dunlap (Australian Institute of Marine Science) prepared and donated the MAA standards. J. Dearborn (University of Maine) provided editorial advice and a 'general reader's' perspective. Four reviewers provided helpful comments. Our research was supported by the Centre Scientifique de Monaco, by the National Geographic Society, and in part by U.S. National Science Foundation grant OCE9907305.

\section{LITERATURE CITED}

Adams NL, Shick JM (1996) Mycosporine-like amino acids provide protection against ultraviolet radiation in eggs of the green sea urchin, Strongylocentrotus droebachiensis. Photochem Photobiol 64:149-158

Adams NL, Shick JM (2001) Mycosporine-like amino acids prevent UVB-induced abnormalities during early development of the green sea urchin Strongylocentrotus droebachiensis. Mar Biol 138:267-280

Allemand D, Furla P, Bénazet-Tambutté S (1998) Mechanisms of carbon acquisition for endosymbiont photosynthesis in Anthozoa. Can J Bot 76:925-941

Anderson S, Zepp RG, Machula J, Santavy D, Hansen L, Mueller E (2001) Indicators of UV exposure in corals and their relevance to global climate change and bleaching. Human Ecol Risk Assess 7:1271-1282

Baker AC (2003) Flexibility and specificity in coral-algal symbiosis: diversity, ecology, and biogeography of Symbiodinium. Annu Rev Ecol Evol Syst 34:661-689

Baker AC (2004) Symbiont diversity on coral reefs and its relationship to bleaching resistance and resilience. In: Rosenberg E, Loya Y (eds) Coral health and disease. Springer-Verlag, Berlin, p 177-194

Banaszak AT (2003) Photoprotective physiological and biochemical responses of aquatic organisms. In: Helbling EW, Zagarese HE (eds) UV effects in aquatic organisms and ecosystems, Vol I. In: Häder DP, Jori G (eds) Comprehensive series in photochemistry and photobiology. Cambridge University Press, Cambridge, p 329-356

Banaszak AT, Trench RK (1995) Effects of ultraviolet (UV) radiation on marine microalgal-invertebrate symbioses. II. The synthesis of mycosporine-like amino acids in response to exposure to UV in Anthopleura elegantissima and Cassiopeia xamachana. J Exp Mar Biol Ecol 194: 233-250

Banaszak AT, Lesser MP, Kuffner IB, Ondrusek M (1998) Relationship between ultraviolet (UV) radiation and mycosporine-like amino acids (MAAs) in marine organisms. Bull Mar Sci 63:617-628

Banaszak AT, LaJeunesse TC, Trench RK (2000) The synthesis of mycosporine-like amino acids (MAAs) by cultured, symbiotic dinoflagellates. J Exp Mar Biol Ecol 249: 219-233

Blank RJ (1987) Cell architecture of the dinoflagellate Symbiodinium sp. inhabiting the Hawaiian coral Montipora verrucosa. Mar Biol 94:143-155

Carreto JI, Lutz VA, De Marco SG, Carignan MO (1990) Fluence and wavelength dependence of mycosporine-like amino acid synthesis in the dinoflagellate Alexandrium excavatum. In: Graneli E, Sundström B, Edler L, Anderson 
DM (eds) Toxic marine phytoplankton. Elsevier, Amsterdam, p 275-279

Carroll AK, Shick JM (1996) Dietary accumulation of mycosporine-like amino acids (MAAs) by the green sea urchin (Strongylocentrotus droebachiensis). Mar Biol 124: 561-569

Conde FR, Churio MS, Previtali CM (2000) The photoprotector mechanism of mycosporine-like amino acids. Excitedstate properties and photostability of porphyra-334 in aqueous solution. J Photochem Photobiol B: Biol 56: $139-144$

Conde, FR, Churio, MS, Previtali, CM (2004) The deactivation pathways of the excited-states of the mycosporine-like amino acids shinorine and porphyra-334 in aqueous solution. Photochem Photobiol Sci 3:960-967

Dunlap WC, Shick JM (1998) Ultraviolet radiation-absorbing mycosporine-like amino acids in coral reef organisms: a biochemical and environmental perspective. J Phycol 34: 418-430

Dunlap WC, Chalker BE, Oliver JK (1986) Bathymetric adaptations of reef building corals at Davies Reef, Australia. III. UV-B absorbing compounds. J Exp Mar Biol Ecol 104: 239-248

Edmunds PJ, Gates RD (2002) Normalizing physiological data for scleractinian corals. Coral Reefs 21:193-197

Edmunds PJ, Gates RD (2003) Has coral bleaching delayed our understanding of fundamental aspects of coraldinoflagellate symbioses? BioScience 53:976-980

Falkowski PG, Dubinsky Z, Muscatine L, McCloskey LR (1993) Population control in symbiotic corals: ammonium ions and organic materials maintain the density of zooxanthellae. BioScience 43:606-611

Ferrier-Pagès C, Witting J, Tambutté E, Sebens KP (2003) Effect of natural zooplankton feeding on the tissue and skeletal growth of the scleractinian coral Stylophora pistillata. Coral Reefs 22:229-240

Franklin LA, Yakoleva I, Karsten U, Lüning K (1999) Synthesis of mycosporine-like amino acids in Chondrus crispus (Florideophyceae) and the consequences for sensitivity to ultraviolet B radiation. J Phycol 35:682-693

Franzisket L (1970) The atrophy of hermatypic reef corals maintained in darkness and their subsequent regeneration in light. Int Rev Gesamten Hydrobiol 55:1-12

Gleason DF (1993) Differential effects of ultraviolet radiation on green and brown morphs of the Caribbean coral Porites astreoides. Limnol Oceanogr 38:1452-1463

Gleason DF (2001) Ultraviolet radiation and coral communities. In: Cockell CS, Blaustein AR (eds) Ecosystems, evolution, and ultraviolet radiation. Springer-Verlag, New York, p 118-149

Gleason DF, Wellington GM (1995) Variation in UVB sensitivity of planula larvae of the coral Agaricia agaricites along a depth gradient. Mar Biol 123:693-703

Goiran C, Al-Moghrabi S, Allemand D, Jaubert J (1996) Inorganic carbon uptake for photosynthesis by the symbiotic coral/dinoflagellate association 1. Photosynthetic performances of symbionts and dependence on sea water bicarbonate. J Exp Mar Biol Ecol 199:207-225

Grant PT, Middleton C, Plack PA, Thomson RH (1985) The isolation of four aminocyclohexenimines (mycosporines) and a structurally related derivative of cyclohexane-1:3dione (gadusol) from the brine shrimp, Artemia. Comp Biochem Physiol 80B:755-759

Grover R, Maguer JF, Reynaud-Vaganay S, Ferrier-Pagès C (2002) Uptake of ammonium by the scleractinian coral Stylophora pistillata: effect of feeding, light, and ammonium concentrations. Limnol Oceanogr 47:782-790
Halldal P (1968) Photosynthetic capacities and photosynthetic action spectra of endozoic algae of the massive coral Favia. Biol Bull (Woods Hole) 134:411-424

Haslam E (1993) Shikimic acid: metabolism and metabolites. John Wiley \& Sons, New York

Hoegh-Guldberg O (1999) Climate change, coral bleaching and the future of the worlds coral reefs. Mar Freshw Res 50:839-866

Hoegh-Guldberg O, Williamson J (1999) Availability of two forms of dissolved nitrogen to the coral Pocillopora damicornis and its symbiotic zooxanthellae. Mar Biol 133: 561-570

Houlbrèque F, Tambutté E, Ferrier-Pagès C (2003) Effect of zooplankton availability on the rates of photosynthesis, and tissue and skeletal growth in the scleractinian coral Stylophora pistillata. J Exp Mar Biol Ecol 296:145-166

Jokiel PL (2004) Temperature stress and coral bleaching. In: Rosenberg E, Loya Y (eds) Coral health and disease. Springer-Verlag, Berlin, p 401-425

Jokiel PL, Lesser MP, Ondrusek ME (1997) UV-absorbing compounds in the coral Pocillopora damicornis: interactive effects of UV radiation, photosynthetically active radiation, and water flow. Limnol Oceanogr 42:1468-1473

Jones RJ, Hoegh-Guldberg O, Larkum A, Schreiber U (1998) Temperature-induced bleaching of corals begins with impairment of the $\mathrm{CO}_{2}$ fixation mechanism in zooxanthellae. Plant Cell Environ 21:1219-1230

Karentz D (2001) Chemical defenses of marine organisms against solar radiation exposure: UV-absorbing mycosporine-like amino acids and scytonemin. In: McClintock JB, Baker BJ (eds) Marine chemical ecology. CRC Press, Boca Raton, FL, p 481-520

Karsten U, Franklin LA, Lüning K, Wiencke C (1998) Natural ultraviolet radiation and photosynthetically active radiation induce formation of mycosporine-like amino acids in the marine macroalga Chondrus crispus (Rhodophyta). Planta 205:257-262

Knowlton N, Rohwer F (2003) Multispecies microbial mutualisms on coral reefs: the host as habitat. Am Nat 162: S51-S62

LaJeunesse TC (2001) Investigating the biodiversity, ecology, and phylogeny of endosymbiotic dinoflagellates in the genus Symbiodinium using the ITS region: in search of a 'species' level marker. J Phycol 37:866-880

LaJeunesse TC (2002) Diversity and community structure of symbiotic dinoflagellates from Caribbean coral reefs. Mar Biol 141:387-400

Lesser MP (2004) Experimental biology of coral reef ecosystems. J Exp Mar Biol Ecol 300:217-252

Lesser MP, Farrell JH (2004) Exposure to solar radiation increases damage to both host tissues and algal symbionts of corals during thermal stress. Coral Reefs 23:367-377

Michalek-Wagner K (2001) Seasonal and sex-specific variations in levels of photo-protecting mycosporine-like amino acids (MAAs) in soft corals. Mar Biol 139:651-660

Neale PJ, Banaszak AT, Jarriel CR (1998) Ultraviolet sunscreens in Gymnodinium sanguineum (Dinophyceae): mycosporine-like amino acids protect against inhibition of photosynthesis. J Phycol 34:928-938

Newman SJ, Dunlap WC, Nicol S, Ritz D (2000) Antarctic krill (Euphausia superba) acquire UV-absorbing mycosporinelike amino acids from dietary algae. J Exp Mar Biol Ecol 255:93-110

Portwich A, Garcia-Pichel F (1999) Ultraviolet and osmotic stresses induce and regulate the synthesis of mycosporines in the cyanobacterium Chlorogloeopsis PCC 6912. Arch Microbiol 172:187-192 
Portwich A, Garcia-Pichel F (2000) A novel prokaryotic UVB photoreceptor in the cyanobacterium Chlorogloeopsis PCC 6912. Photochem Photobiol 71:493-498

Portwich A, Garcia-Pichel F (2003) Biosynthetic pathway of mycosporines (mycosporine-like amino acids) in the cyanobacterium Chlorogloeopsis sp. strain PCC 6912. Phycologia 42:384-392

Rahav O, Dubinsky Z, Achituv Y, Falkowski PG (1989) Ammonium metabolism in the zooxanthellate coral Stylophora pistillata. Proc R Soc Lond B 236:325-337

Raven JA (1991) Responses of aquatic photosynthetic organisms to increased solar UVB. J Photochem Photobiol B 9: 239-244

Romaine-Lioud S, Tambutté E, Allemand D, Gattuso JP (1997) Photosynthesis, respiration and calcification of a zooxanthellate scleractinian coral under submerged and exposed conditions. Mar Biol 129:175-182

Santos SR, Taylor DJ, Coffroth MA (2001) Genetic comparisons of freshly isolated versus cultured symbiotic dinoflagellates: implications for extrapolating to the intact symbiosis. J Phycol 37:900-912

Shick JM (2004) The continuity and intensity of ultraviolet radiation affect the kinetics of biosynthesis, accumulation, and conversion of mycosporine-like amino acids (MAAs) in the coral Stylophora pistillata. Limnol Oceanogr 49: $442-458$

Shick JM, Dunlap WC (2002) Mycosporine-like amino acids and related gadusols: biosynthesis, accumulation, and UV-protective functions in aquatic organisms. Annu Rev Physiol 64:223-262

Shick JM, Lesser MP, Dunlap WC, Stochaj WR, Chalker BE, Wu Won J (1995) Depth-dependent responses to solar ultraviolet radiation and oxidative stress in the zooxanthellate coral Acropora microphthalma. Mar Biol 122: $41-51$

Shick JM, Lesser MP, Jokiel PL (1996) Effects of ultraviolet radiation on corals and other coral reef organisms. Global Change Biol 2:527-545

Shick JM, Romaine-Lioud S, Ferrier-Pagès C, Gattuso JP (1999) Ultraviolet-B radiation stimulates shikimate pathway-dependent accumulation of mycosporine-like amino acids in the coral Stylophora pistillata despite decreases in its population of symbiotic dinoflagellates. Limnol Oceanogr 44:1667-1682

Shick JM, Dunlap WC, Buettner GR (2000) Ultraviolet (UV)

Editorial responsibility: Otto Kinne (Editor-in-Chief), Oldendorf/Luhe, Germany protection in marine organisms. II. Biosynthesis, accumulation, and sunscreening function of mycosporine-like amino acids. In: Yoshikawa S, Toyokuni S, Yamamoto Y, Naito Y (eds) Free radicals in chemistry, biology and medicine. OICA International, London, p 215-228

Shick JM, Dunlap WC, Pearse JS, Pearse VB (2002) Mycosporine-like amino acid content in four species of sea anemones in the genus Anthopleura reflects phylogenetic but not environmental or symbiotic relationships. Biol Bull (Woods Hole) 203:315-330

Steen RG (1986) Evidence for heterotrophy by zooxanthellae in symbiosis with Aiptasia pulchella. Biol Bull (Woods Hole) 170:267-278

Stochaj WR, Grossman AR (1997) Differences in the protein profiles of cultured and endosymbiotic Symbiodinium sp. (Pyrrophyta) from the anemone Aiptasia pallida (Anthozoa). J Phycol 33:44-53

Stramski D, Morel A (1990) Optical properties of photosynthetic picoplankton in different physiological states as affected by growth irradiance. Deep-Sea Res 37:245-266

Tartarotti B, Sommaruga R (2002) The effect of different methanol concentrations and temperatures on the extraction of mycosporine-like amino acids in algae and zooplankton. Arch Hydrobiol 154:691-703

Titlyanov EA, Titlyanova TV, Yamazato K, Van Woesik R (2001) Photo-acclimation of the hermatypic coral Stylophora pistillata while subjected to either starvation or food provisioning. J Exp Mar Biol Ecol. 257:163-181

Trench RK (1993) Microalgal-invertebrate symbioses: a review. Endocytobiosis Cell Res 9:135-175

Vandermeulen JH, Davis ND, Muscatine L (1972) The effect of inhibitors of photosynthesis on zooxanthellae in corals and other marine invertebrates. Mar Biol 16:185-191

Warner ME, Fitt WK, Schmidt GW (1999) Damage to photosystem II in symbiotic dinoflagellates: a determinant of coral bleaching. Proc Natl Acad Sci USA 96:8007-8012

Whitehead K, Karentz D, Hedges JI (2001) Mycosporine-like amino acids (MAAs) in phytoplankton, a herbivorous pteropod (Limacina helicina), and its pteropod predator (Clione antarctica) in McMurdo Bay, Antarctica. Mar Biol 139:1013-1019

Yakoleva I, Hidaka M (2004) Differential recovery of PSII function and electron transport rate in symbiotic dinoflagellates as a possible determinant of bleaching susceptibility of corals. Mar Ecol Prog Ser 268:43-53

Submitted: July 22, 2004; Accepted: December 11, 2004 Proofs received from author(s): May 30, 2005 